\title{
Sulfur dioxide retrievals from TROPOMI onboard Sentinel-5 Precursor: algorithm theoretical basis
}

\author{
Nicolas Theys ${ }^{1}$, Isabelle De Smedt ${ }^{1}$, Huan Yu ${ }^{1}$, Thomas Danckaert ${ }^{1}$, Jeroen van Gent ${ }^{1}$, Christoph Hörmann ${ }^{2}$, \\ Thomas Wagner ${ }^{2}$, Pascal Hedelt ${ }^{3}$, Heiko Bauer ${ }^{3}$, Fabian Romahn ${ }^{3}$, Mattia Pedergnana ${ }^{3}$, Diego Loyola ${ }^{3}$, and \\ Michel Van Roozendael ${ }^{1}$ \\ ${ }^{1}$ Royal Belgian Institute for Space Aeronomy (BIRA-IASB), Brussels, Belgium \\ ${ }^{2}$ Max Planck Institute for Chemistry (MPIC), Hahn-Meitner-Weg 1, 55128 Mainz, Germany \\ ${ }^{3}$ Institut für Methodik der Fernerkundung (IMF), Deutsches Zentrum für Luft und Raumfahrt (DLR), \\ Oberpfaffenhofen, Germany \\ Correspondence to: N. Theys (theys@aeronomie.be)
}

Received: 21 September 2016 - Published in Atmos. Meas. Tech. Discuss.: 22 September 2016

Revised: 19 November 2016 - Accepted: 12 December 2016 - Published: 9 January 2017

\begin{abstract}
The TROPOspheric Monitoring Instrument (TROPOMI) onboard the Copernicus Sentinel-5 Precursor (S-5P) platform will measure ultraviolet earthshine radiances at high spectral and improved spatial resolution (pixel size of $7 \mathrm{~km} \times 3.5 \mathrm{~km}$ at nadir) compared to its predecessors OMI and GOME-2. This paper presents the sulfur dioxide $\left(\mathrm{SO}_{2}\right)$ vertical column retrieval algorithm implemented in the S-5P operational processor UPAS (Universal Processor for UV/VIS Atmospheric Spectrometers) and comprehensively describes its various retrieval steps. The spectral fitting is performed using the differential optical absorption spectroscopy (DOAS) method including multiple fitting windows to cope with the large range of atmospheric $\mathrm{SO}_{2}$ columns encountered. It is followed by a slant column background correction scheme to reduce possible biases or across-track-dependent artifacts in the data. The $\mathrm{SO}_{2}$ vertical columns are obtained by applying air mass factors (AMFs) calculated for a set of representative a priori profiles and accounting for various parameters influencing the retrieval sensitivity to $\mathrm{SO}_{2}$. Finally, the algorithm includes an error analysis module which is fully described here. We also discuss verification results (as part of the algorithm development) and future validation needs of the TROPOMI $\mathrm{SO}_{2}$ algorithm.
\end{abstract}

\section{Introduction}

Sulfur dioxide enters the Earth's atmosphere via both natural and anthropogenic processes. Through the formation of sulfate aerosols and sulfuric acid, it plays an important role on the chemistry at local and global scales and its impact ranges from short-term pollution to climate forcing. While about one-third of the global sulfur emissions originate from natural sources (volcanoes and biogenic dimethyl sulfide), the main contributor to the total budget is from anthropogenic emissions mainly from the combustion of fossil fuels (coal and oil) and from smelting. Over the last decades, a host of satellite-based UV-visible instruments have been used for the monitoring of anthropogenic and volcanic $\mathrm{SO}_{2}$ emissions. Total vertical column density (VCD) of $\mathrm{SO}_{2}$ has been retrieved with the sensors TOMS (Krueger, 1983), GOME (Eisinger and Burrows, 1998; Thomas et al., 2005; Khokar et al., 2005), SCIAMACHY (Afe et al., 2004), OMI (Krotkov et al., 2006; Yang et al., 2007, 2010; Li et al., 2013; Theys et al., 2015), GOME-2 (Richter et al., 2009; Bobrowski et al., 2010; Nowlan et al., 2011; Rix et al., 2012; Hörmann et al., 2013) and OMPS (Yang et al., 2013). In particular, the Ozone Monitoring Instrument (OMI) has largely demonstrated the value of satellite UV-visible remote sensing (1) in monitoring volcanic plumes in near-real time (Brenot et al., 2014) and changes in volcanic degassing at the global scale (Carn et al., 2016, and references therein) and (2) in detecting and quantifying large anthropogenic $\mathrm{SO}_{2}$ emissions, weak or 


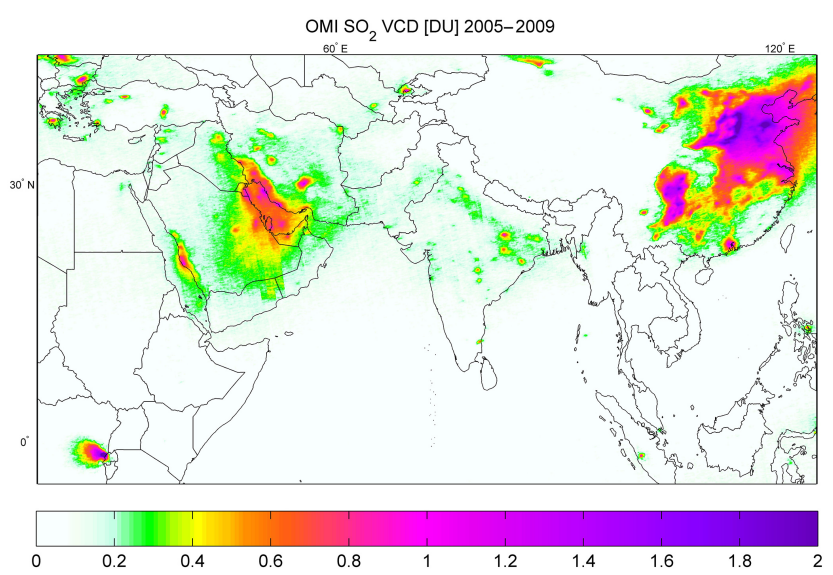

Figure 1. Map of averaged $\mathrm{SO}_{2}$ columns from OMI clear-sky pixels for the 2005-2009 period.

unreported emission sources worldwide (Theys et al., 2015; Fioletov et al., 2016; McLinden et al., 2016) as well as investigating their long-term changes (Krotkov et al., 2016; van der A et al., 2016; He et al., 2016). An example map of $\mathrm{OMI} \mathrm{SO}_{2}$ columns (Theys et al., 2015) averaged over the 2005-2009 period is shown in Fig. 1, illustrating typical anthropogenic emission hotspots (China, eastern Europe, India and the Middle East) and signals from volcanic activity (e.g., from the volcanoes in DR Congo).

The 7-year-lifetime Sentinel-5p sensor TROPOMI (Veefkind et al., 2012) will fly on a polar low-Earth orbit with a wide swath of $2600 \mathrm{~km}$. The TROPOMI instrument is a push-broom imaging spectrometer similar in concept to OMI. It has eight spectral bands covering UV to SWIR wavelengths. The $\mathrm{SO}_{2}$ retrieval algorithm exploits measurements from band $3(310-405 \mathrm{~nm})$, with typical spectral resolution of $0.54 \mathrm{~nm}$, signal-to-noise ratio of about 1000 and pixel size as good as $7 \mathrm{~km} \times 3.5 \mathrm{~km}$.

TROPOMI will continue and improve the measurement time series of $\mathrm{OMI} \mathrm{SO}_{2}$ and other UV sensors. Owing to similar performance to $\mathrm{OMI}$ in terms of signal-to-noise ratio and unprecedented spatial resolution, TROPOMI will arguably discern very fine details in the $\mathrm{SO}_{2}$ distribution and will be able to detect point sources with annual $\mathrm{SO}_{2}$ emissions of about $10 \mathrm{kT} \mathrm{yr}^{-1}$ or lower (using oversampling techniques).

This paper gives a thorough description of the operational TROPOMI SO $\mathrm{S}_{2}$ algorithm and reflects the S-5P SO $2 \mathrm{~L} 2 \mathrm{Al}-$ gorithm Theoretical Basis Document v1.0. In Sect. 2, we first present the product requirements and briefly discuss the expected product performance in terms of precision and accuracy. It is then followed by the $\mathrm{SO}_{2}$ column retrieval algorithm description. An error analysis of the retrieval method is presented in Sect. 3. Results from algorithm verification exercise using an independent retrieval scheme is given in Sect. 4. The possibilities for future validation of the retrieved $\mathrm{SO}_{2}$ data product can be found in Sect. 5. Conclusions are given in Sect. 6. Additional information on data product and auxiliary data, as well as a list of acronyms, is provided in the Appendix.

\section{TROPOMI $\mathrm{SO}_{2}$ algorithm}

\subsection{Product requirements}

While UV measurements are highly sensitive to $\mathrm{SO}_{2}$ at high altitudes (upper troposphere-lower stratosphere), the sensitivity to $\mathrm{SO}_{2}$ concentration in the boundary layer is intrinsically limited from space due to the combined effect of scattering (Rayleigh and Mie) and ozone absorption that hamper the penetration of solar radiation into the lowest atmospheric layers. Furthermore, the $\mathrm{SO}_{2}$ absorption signature suffers from the interference with the ozone absorption spectrum.

The retrieval precision (or random uncertainty) is driven by the signal-to-noise ratio of the recorded spectra and by the retrieval wavelength interval used, the accuracy (or systematic uncertainty) is limited by the knowledge on the auxiliary parameters needed in the different retrieval steps. Among these are the treatment of other chemical interfering species, clouds and aerosol, the representation of vertical profiles (gas, temperature, pressure), and uncertainties on data from external sources (e.g., surface reflectance).

Requirements on the accuracy and precision for the data products derived from the TROPOMI measurements are specified in the GMES Sentinels 4 and 5 and 5 p Mission Requirements Document MRD (Langen et al., 2011), the Report of The Review Of User Requirements for Sentinels4/5 (Bovensmann et al., 2011) and the Science Requirements Document for TROPOMI (van Weele et al., 2008). These requirements derive from the Composition of the Atmosphere: Progress to Applications in the user CommunITY (CAPACITY) study (Kelder et al., 2005) and have been fine-tuned by the Composition of the Atmospheric Mission concEpts and SentineL Observation Techniques (CAMELOT; Levelt et al., 2009) and Original and New TRopospheric composition and Air Quality measurements (ONTRAQ; Zweers et al., 2010) studies. The CAPACITY study has defined three main themes: the ozone layer (A), air quality (B), and climate (C), with further division into sub-themes. Requirements for $\mathrm{SO}_{2}$ have been specified for a number of these sub-themes. In the following paragraphs, we discuss these requirements and the expected performances of the $\mathrm{SO}_{2}$ retrieval algorithm (summary is given in Table 1).

\subsubsection{Theme A3 - ozone layer assessment}

This theme addresses the importance of measurements in the case of enhanced $\mathrm{SO}_{2}$ concentrations in the stratosphere due to severe volcanic events. The long-term presence (up to several months) of $\mathrm{SO}_{2}$ in the stratosphere contributes to the stratospheric aerosol loading and hence affects the cli- 
Table 1. Requirements on $\mathrm{SO}_{2}$ vertical column products as derived from the MRD. Left- and right-hand numbers in ranges denote accuracy and precision, respectively.

\begin{tabular}{|c|c|c|c|c|}
\hline & $\begin{array}{r}\text { Horizontal } \\
\text { resolution } \\
(\mathrm{km})\end{array}$ & $\begin{array}{l}\text { Required } \\
\text { uncertainty }\end{array}$ & $\begin{array}{l}\text { Achievable } \\
\text { uncertainty }\end{array}$ & $\begin{array}{l}\text { Theme } \\
\text { (table in } \\
\text { MRTD) }\end{array}$ \\
\hline $\begin{array}{l}\text { Enhanced stratospheric } \\
\text { column }\end{array}$ & $50-200$ & $\begin{array}{l}30 \% \text { for } \\
\mathrm{VCD}>0.5 \mathrm{DU}\end{array}$ & $\begin{array}{l}\text { Met for VCD }>0.5 \mathrm{DU} \\
\mathrm{VCD}>0.5 \mathrm{DU}\end{array}$ & A3 \\
\hline $\begin{array}{l}\text { Tropospheric } \\
\text { column }\end{array}$ & $5-20$ & $\begin{array}{l}30-60 \% \text { or } \\
1.3 \times 10^{15} \text { molecules } \mathrm{cm}^{-2} \\
\text { (least stringent) }\end{array}$ & $\begin{array}{l}50 \% / \\
3-6 \times 10^{16} \text { molecules } \mathrm{cm}^{-2}\end{array}$ & $\mathrm{~B} 1, \mathrm{~B} 2, \mathrm{~B} 3$ \\
\hline Total column & $5-20$ & $\begin{array}{l}30-60 \% \text { or } \\
1.3 \times 10^{15} \text { molecules } \mathrm{cm}^{-2} \\
\text { (least stringent) }\end{array}$ & $\begin{array}{l}50 \% / \\
3-6 \times 10^{16} \text { molecules } \mathrm{cm}^{-2}\end{array}$ & $\mathrm{~B} 1, \mathrm{~B} 2, \mathrm{~B} 3$ \\
\hline
\end{tabular}

mate and the stratospheric ozone budget. For such scenarios, the requirements state that the stratospheric vertical column should be monitored with a total uncertainty of $30 \%$. Although powerful volcanic events generally produce large amounts of $\mathrm{SO}_{2}$, monitoring such a plume over extended periods of time also requires the detection of the plume after it has diluted during the weeks after the eruption.

From an error analysis of the proposed $\mathrm{SO}_{2}$ algorithm (Sect. 3), we have assessed the major sources of uncertainty in the retrieved $\mathrm{SO}_{2}$ column. One of the main contributors to the total uncertainty is instrumental noise. This source of error alone limits the precision to vertical columns above about $0.25 \mathrm{DU}\left(1 \mathrm{DU}=2.69 \times 10^{16}\right.$ molec cm $\left.\mathrm{cm}^{-2}\right)$. For $\mathrm{SO}_{2}$ in the stratosphere, the summing-up of the various uncertainties (Sect. 3) is believed to be around the required uncertainty of $30 \%$ for diluted $\mathrm{SO}_{2}$ plumes, provided that the vertical column is larger than 0.5 DU. Explosive volcanic eruptions capable of injecting $\mathrm{SO}_{2}$ into the stratosphere regularly show stratospheric $\mathrm{SO}_{2}$ columns of a few DU to several hundreds of DU or more, as was the case, for example, for the eruptions of Mt. Kasatochi (Yang et al., 2010) and Sarychev Peak (Carn et al., 2011). For very large $\mathrm{SO}_{2}$ concentrations, the dynamical use of different fitting windows (see Sect. 2.2) enables the $30 \%$ uncertainty level to be reached (see Sect. 4).

\subsubsection{Theme B - air quality}

This theme includes three sub-themes:

B1 Protocol monitoring: this involves the monitoring of abundances and concentrations of atmospheric constituents, driven by several agreements, such as the Gothenburg protocol, National Emission Ceilings, and EU Air Quality regulations.

B2 Near-real-time (NRT) data requirements: this comprises the relatively fast $(\sim 30 \mathrm{~min})$ prediction and determination of surface concentrations in relation to health and safety warnings.
B3 Assessment: this sub-theme aims at answering several air-quality-related scientific questions, such as the effect on air quality of spatial and temporal variations in oxidizing capacity and long-range transport of atmospheric constituents.

A more detailed description of the air quality sub-themes can be found in Langen et al. (2011).

The user requirements on $\mathrm{SO}_{2}$ products are equal for all three sub-themes. For the total vertical column and the tropospheric vertical column of $\mathrm{SO}_{2}$, the user requirements state an absolute maximum uncertainty of $1.3 \times 10^{15}$ molecules $\mathrm{cm}^{-2}$ or $0.05 \mathrm{DU}$. This number derives from the ESA CAPACITY study, where the number was expressed as $0.4 \mathrm{ppbv}$ for a $1.5 \mathrm{~km}$ thick boundary layer reaching up to $850 \mathrm{hPa}$. From the uncertainty due to instrument noise only, it is clear that the $0.05 \mathrm{DU}$ requirement cannot be met on a single-measurement basis. This limitation was already found in the ESA CAMELOT study (Levelt et al., 2009).

For anthropogenic $\mathrm{SO}_{2}$ typically confined in the planetary boundary layer (PBL), calculations performed within the CAMELOT study showed that the smallest vertical column that can be detected in the PBL is of about 1-3 DU (for a signal-to-noise ratio $(S / N)$ of 1000). Although pollution hotspots can be better identified by spatial or temporal averaging, several uncertainties (e.g., due to varying surface albedo or $\mathrm{SO}_{2}$ vertical profile shape) are not averaging out and directly limit the product accuracy to about $50 \%$ or more. Though the difference between the MRD requirements and the expected TROPOMI performance is rather large, one could argue that the required threshold should not be a strict criterion in all circumstances. The user requirement of $0.05 \mathrm{DU}$ represents the maximum uncertainty to distinguish (anthropogenic) pollution sources from background concentrations. Bovensmann et al. (2011) reviewed the MRD user requirements and motivated a relaxation of certain user requirements for specific conditions. For measurements in the PBL, the document proposes a relative 


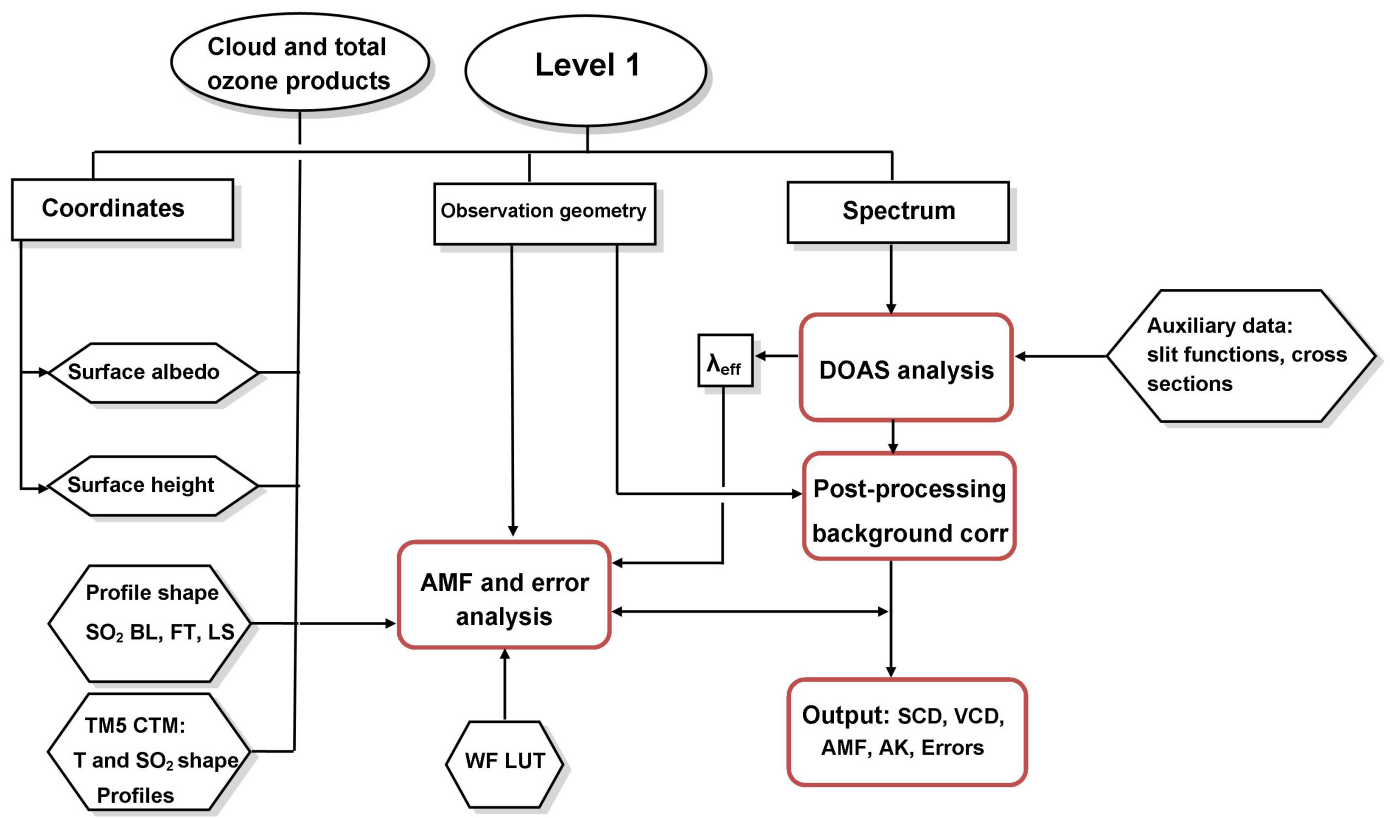

Figure 2. Flow Diagram of the TROPOMI DOAS retrieval algorithm for $\mathrm{SO}_{2}$.

requirement of 30-60\% in order to discriminate between enhanced ( $>1.5 \mathrm{ppbv})$, moderate $(0.5-1.5 \mathrm{ppbv})$, and background concentrations $(<0.5 \mathrm{ppbv})$. It is expected that it will be possible to discriminate these three levels by averaging (spatiotemporally) TROPOMI data.

For volcanic $\mathrm{SO}_{2}$ plumes in the free troposphere, a better measurement sensitivity is expected for TROPOMI. The expected precision is about $0.5 \mathrm{DU}$ on the vertical column. The accuracy on the $\mathrm{SO}_{2}$ vertical column will be strongly limited by the $\mathrm{SO}_{2}$ plume height and the cloud conditions. As these parameters are highly variable in practice, it is difficult to ascertain the product accuracy for these conditions.

\subsection{Algorithm description}

The first algorithm to retrieve $\mathrm{SO}_{2}$ columns from space-borne UV measurements was developed based on a few wavelength pairs (for TOMS) and has been subsequently applied and refined for OMI measurements (e.g., Krotkov et al., 2006; Yang et al., 2007, and references therein). Current algorithms exploit back-scattered radiance measurements in a wide spectral range using a direct fitting approach (Yang et al., 2010; Nowlan et al., 2011), a principal component analysis (PCA) method (Li et al., 2013) or (some form of) differential optical absorption spectroscopy (DOAS; Platt and Stutz, 2008); see, e.g., Richter et al. (2009), Hörmann et al. (2013), or Theys et al. (2015).

Direct fitting schemes in which on-the-fly radiative transfer simulations are made for all concerned wavelengths and resulting simulated spectra are adjusted to the spectral observations, are in principle the most accurate. They are able to cope with very large $\mathrm{SO}_{2}$ columns (such as those occurring during explosive volcanic eruptions), i.e., conditions typically leading to a strongly nonlinear relation between the $\mathrm{SO}_{2}$ signal and the VCD. However, the main disadvantage of direct fitting algorithms with respect to DOAS (or PCA) is that they are computationally expensive and are out of reach for TROPOMI operational near-real-time processing, for which the level $1 \mathrm{~b}$ data flow is expected to be massive and deliver around 1.5 million spectral measurements per orbit ( $\sim 15$ orbits daily) for band 3 (with a corresponding data size of $6 \mathrm{~GB}$ ). To reach the product accuracy and processing performance requirements, the approach adopted here applies DOAS in three different fitting windows (within the 310-390 $\mathrm{nm}$ spectral range) that are still sensitive enough to $\mathrm{SO}_{2}$ but less affected by nonlinear effects (Bobrowski et al., 2010; Hörmann et al., 2013).

Figure 2 shows the full flow diagram of the $\mathrm{SO}_{2}$ retrieval algorithm including the dependencies on auxiliary data and other L2 products. The algorithm and its application to OMI data are also described in Theys et al. (2015), although there are differences in some settings. The baseline operation flow of the scheme is based on a DOAS retrieval algorithm and is identical to that implemented in the retrieval algorithm for HCHO (also developed by BIRA-IASB; see De Smedt et al., 2016). The main output parameters of the algorithm are $\mathrm{SO}_{2}$ vertical column density, slant column density, air mass factor, averaging kernels (AKs) and error estimates. Here, we will first briefly discuss the principle of the DOAS VCD retrieval before discussing the individual steps of the process in more detail.

First, the radiance and irradiance data are read from an $\mathrm{S}$ 5P L1b file, along with geolocation data such as pixel coor- 
dinates and observation geometry (sun and viewing angles). At this stage cloud cover information (see Table A3 in Appendix A) is also obtained from the S-5P cloud L2 data, as required for the calculation of the AMF, later in the scheme. Then relevant absorption cross section data, as well as characteristics of the instrument (e.g., slit functions), are used as input for the determination of $\mathrm{SO}_{2}$ slant column density. As a baseline, the slant column fit is done in a sensitive window from 312 to $326 \mathrm{~nm}$. For pixels with a strong $\mathrm{SO}_{2}$ signal, results from alternative windows where the $\mathrm{SO}_{2}$ absorption is weaker can be used instead. An empirical offset correction (dependent on the fitting window used) is then applied to the SCD. The latter correction accounts for systematic biases in the SCDs. Following the SCD determination, the AMF is estimated based on a pre-calculated weighting functions (or box AMFs) look-up table (LUT). This look-up table is generated using the LInearized Discrete Ordinate Radiative Transfer (LIDORT) code (Spurr, 2008) and has several entries: cloud cover data, topographic information, observation geometry, surface albedo, effective wavelength (representative of the fitting window used), total ozone column and the shape of the vertical $\mathrm{SO}_{2}$ profile. The algorithm also includes an error calculation and retrieval characterization module (Sect. 3) that computes the averaging kernels (Eskes and Boersma, 2003), which characterize the vertical sensitivity of the measurement and which are required for comparison with other types of data (Veefkind et al., 2012).

The final $\mathrm{SO}_{2}$ vertical column is obtained by

$N_{\mathrm{v}}=\frac{N_{\mathrm{s}}-N_{\mathrm{s}}^{\mathrm{back}}}{M}$,

where the main quantities are the vertical column $\left(N_{\mathrm{v}}\right)$, the slant column density $\left(N_{\mathrm{s}}\right)$ and the values used for the background correction $\left(N_{\mathrm{s}}^{\mathrm{back}}\right) . M$ is the air mass factor.

\subsubsection{Slant column retrieval}

The backscattered radiance spectrum recorded by the space instrument differs from the solar spectrum because of the interactions of the photons with the Earth's atmosphere and surface reflection. Hence, the reflectance spectra contains spectral features that can be related to the various absorbing species and their amounts in the atmosphere. The DOAS method aims at the separation of the highly structured trace gas absorption spectra and broadband spectral structures. The technique relies on a number of assumptions that can be summarized as follows:

a. The spectral analysis and atmospheric radiative transfer computations are treated separately by considering one averaged atmospheric light path of the photons traveling from the sun to the instrument.

b. The absorption cross sections are not strongly dependent on pressure and temperature. Additionally, the averaged light path should be weakly dependent on the wavelength - for the fitting window used - which enables defining an effective absorption (slant) column density. It should be noted that this is not strictly valid for the $\mathrm{SO}_{2}$ DOAS retrieval because of strong absorption by ozone and in some cases $\mathrm{SO}_{2}$ itself (for large $\mathrm{SO}_{2}$ amounts).

c. Spectrally smoothed structures due broadband absorption, scattering and reflection processes can be well reproduced by a low-order polynomial as a function of wavelength.

Photons collected by the satellite instrument may have followed very different light paths through the atmosphere depending on their scattering history. However, a single effective light path is assumed, which represents an average of the complex paths of all reflected and scattered solar photons reaching the instrument within the spectral interval used for the retrieval. This simplification is valid if the effective light path is reasonably constant over the considered wavelength range. The spectral analysis can be described by the following equation:

$\ln \frac{\pi I(\lambda)}{\mu_{0} E_{0}(\lambda)}=-\sum_{j} \sigma_{j}(\lambda) \mathrm{Ns}_{j}+\sum_{p} c_{p} \lambda^{p}$,

where $I(\lambda)$ is the observed backscattered earthshine radiance $\left(\mathrm{W} \mathrm{m}^{-2} \mathrm{~nm}^{-1} \mathrm{sr}^{-1}\right), E_{0}$ is the solar irradiance $\left(\mathrm{W} \mathrm{m}^{-2} \mathrm{~nm}^{-1}\right.$ ) and $\mu_{0}=\cos \theta_{0}$. The first term on the righthand side indicates all relevant absorbing species with absorption cross sections $\sigma_{j}\left(\mathrm{~cm}^{2}\right.$ molec $\left.^{-1}\right)$. Integration of the number densities of these species along the effective light path gives the slant column density $\mathrm{Ns}_{j}\left(\right.$ molec $\left.\mathrm{cm}^{-2}\right)$. Equation (2) can be solved by least-squares fitting techniques (Platt and Stutz, 2008) for the slant column values. The final term in Eq. (2) is the polynomial representing broadband absorption and (Rayleigh and Mie) scattering structures in the observed spectrum and also accounts for possible errors such as uncorrected instrument degradation effects, uncertainties in the radiometric calibration or possible residual (smooth) polarization response effects not accounted for in the level 0-1 processing.

Apart from the cross sections for the trace gases of interest, additional fit parameters need to be introduced to account for the effect of several physical phenomena on the fit result. For $\mathrm{SO}_{2}$ fitting, these are the filling-in of Fraunhofer lines (Ring effect) and the need for an intensity offset correction. In the above, we have assumed that for the ensemble of observed photons a single effective light path can be assumed over the adopted wavelength fitting interval. For the observation of (generally small) $\mathrm{SO}_{2}$ concentrations at large solar zenith angles (SZAs) this is not necessarily the case. For such long light paths, the large contribution of $\mathrm{O}_{3}$ absorption may lead to negative $\mathrm{SO}_{2}$ retrievals. This may be mitigated by taking the wavelength dependence of the $\mathrm{O}_{3} \mathrm{SCD}$ over the 
Table 2. DOAS settings used to retrieved $\mathrm{SO}_{2}$ slant columns.

\begin{tabular}{|c|c|}
\hline Fitting intervals 1 and 2 & $312-326 \mathrm{~nm}(\mathrm{w} 1), 325-335 \mathrm{~nm}(\mathrm{w} 2)$ \\
\hline \multirow[t]{5}{*}{ Cross sections } & $\mathrm{SO}_{2}: 203 \mathrm{~K}$ (Bogumil et al., 2003) \\
\hline & $\mathrm{O}_{3}: 228$ and $243 \mathrm{~K}$ with Io correction (Brion et al., 1998) \\
\hline & Pseudo- $\mathrm{O}_{3}$ cross sections $\left(\lambda \sigma_{O 3}, \sigma_{O 3}^{2}\right.$; Pukīte et al., 2010) \\
\hline & Ring effect: two eigenvectors (Vountas et al., 1998) generated for 20 and \\
\hline & $87^{\circ}$ solar zenith angles using LIDORT-RRS (Spurr et al., 2008) \\
\hline Polynomial & Fifth order \\
\hline Fitting interval 3 & $360-390 \mathrm{~nm}(\mathrm{w} 3)$ \\
\hline \multirow[t]{4}{*}{ Cross sections } & $\mathrm{SO}_{2}$ : Hermans et al. (2009) extrapolated at $203 \mathrm{~K}$ \\
\hline & $\mathrm{NO}_{2}: 220 \mathrm{~K}$ (Vandaele et al., 1998) \\
\hline & $\mathrm{O}_{2}-\mathrm{O}_{2:}$ Greenblatt et al.,1990 \\
\hline & Ring effect: single spectrum (Chance and Spurr, 1997) \\
\hline Polynomial & Fourth order \\
\hline Intensity offset correction & Linear offset \\
\hline Spectrum shift and stretch & Fitted \\
\hline Spectral spikes removal procedure & Richter et al. (2011) \\
\hline \multirow{2}{*}{ Reference spectrum } & Baseline: daily solar irradiance \\
\hline & $\begin{array}{l}\text { Foreseen update: daily averaged earthshine spectrum in Pacific region } \\
\left(10^{\circ} \mathrm{S}-10^{\circ} \mathrm{N}, 160^{\circ} \mathrm{E}-120^{\circ} \mathrm{W}\right) \text {; separate spectrum for each detector row. } \\
\text { NRT: averaged spectra of the last available day; offline: averaged spectra of } \\
\text { the current day }\end{array}$ \\
\hline
\end{tabular}

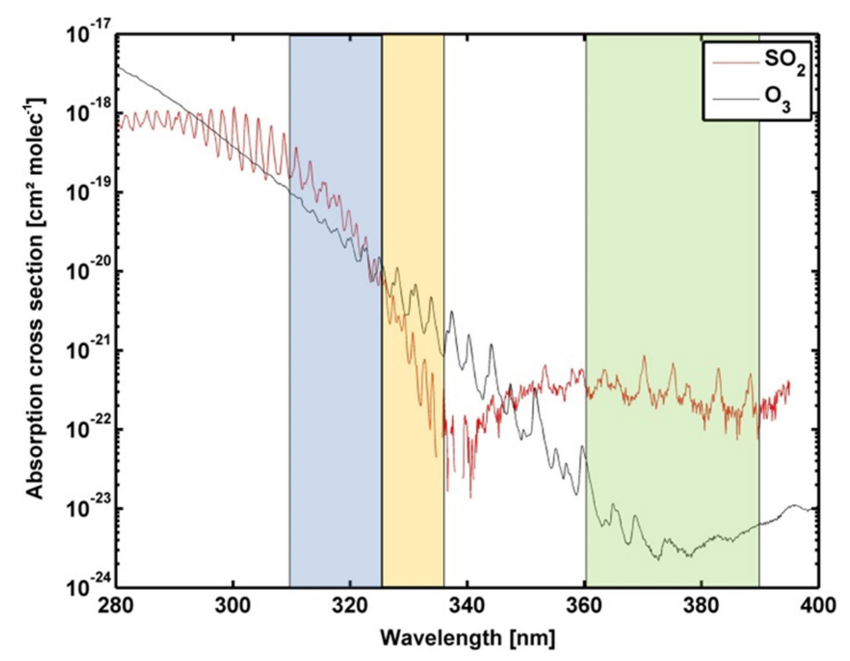

Figure 3. Absorption cross sections of $\mathrm{SO}_{2}$ and $\mathrm{O}_{3}$. The blue, yellow and green boxes delimit the three $\mathrm{SO}_{2}$ fitting windows 312 $326,325-335$ and $360-390 \mathrm{~nm}$, respectively.

fitting window into account, as will be described in the next section.

The different parts of the DOAS retrieval are detailed in the next subsections and Table 2 gives a summary of settings used to invert $\mathrm{SO}_{2}$ slant columns. Note that, in Eq. (2), the daily solar irradiance is used as a baseline for the reference spectrum. As a better option, it is generally preferred to use daily averaged radiances, selected for each across-track position, in the equatorial Pacific. In the NRT algorithm, the last valid day can be used to derive the reference spectra, while in the offline version of the algorithm, the current day should be used. Based on OMI experience, it would allow, for example, for better handling of instrumental artifacts and degradation of the recorded spectra for each detector. At the time of writing, it is planned to test this option during the S-5P commissioning phase.

\section{Wavelength fitting windows}

DOAS measurements are in principle applicable to all gases having suitable narrow absorption bands in the UV, visible, or near-IR regions. However, the generally low concentrations of these compounds in the atmosphere, and the limited signal-to-noise ratio of the spectrometers, restrict the number of trace gases that can be detected. Many spectral regions contain several interfering absorbers and correlations between absorber cross sections can sometimes lead to systematic biases in the retrieved slant columns. In general, the correlation between cross sections decreases if the wavelength interval is extended, but then the assumption of a single effective light path defined for the entire wavelength interval may not be fully satisfied, leading to systematic misfit effects that may also introduce biases in the retrieved slant columns (e.g., Pukīţe et al., 2010) . To optimize DOAS retrieval settings, a trade-off has to be found between these effects. In the UV-visible spectral region, the cross-section spectrum of $\mathrm{SO}_{2}$ has its strongest bands in the $280-320 \mathrm{~nm}$ range (Fig. 3). For the short wavelengths in this range, the $\mathrm{SO}_{2}$ signal, however, suffers from a strong increase in Rayleigh scattering and ozone absorption. In practice, this leads to a very small $\mathrm{SO}_{2}$ signal in the satellite spectra compared to ozone absorp- 
tion, especially for tropospheric $\mathrm{SO}_{2}$. Consequently, $\mathrm{SO}_{2}$ is traditionally retrieved (for GOME, SCIAMACHY, GOME2 , OMI) using sensitive windows in the $310-326 \mathrm{~nm}$ range. Note that even in this range the $\mathrm{SO}_{2}$ absorption can be 3 orders of magnitude lower than that of ozone.

The TROPOMI $\mathrm{SO}_{2}$ algorithm is using a multiple-window approach:

- 312-326 nm: classical fitting window, ideal for small columns. This window is used as baseline. If nonlinear effects due to high $\mathrm{SO}_{2}$ amounts are encountered, one of the two following windows will be used instead.

- 325-335 nm: in this window, differential $\mathrm{SO}_{2}$ spectral features are 1 order of magnitude smaller than in the classical window. It allows the retrieval of moderate $\mathrm{SO}_{2}$ columns, an approach similar to the one described by Hörmann et al. (2013).

- 360-390 nm: $\mathrm{SO}_{2}$ absorption bands are 2-3 orders of magnitude weaker than in the classical window and are best suited for the retrieval of extremely high $\mathrm{SO}_{2}$ columns (Bobrowski et al., 2010)

Note that in the $325-335$ and $360-390 \mathrm{~nm}$ windows the Rayleigh scattering and ozone absorption are less important than in the baseline $312-326 \mathrm{~nm}$ window (see also Fig. 3).

Specifically, in the first two intervals, absorption cross sections of $\mathrm{O}_{3}$ at 228 and $243 \mathrm{~K}$ are included in the fit and, to better cope with the strong (nonlinear) ozone absorption at short wavelengths, the retrieval also includes two pseudocross sections following the approach of Pukite et al. (2010): $\lambda \sigma_{\mathrm{O}_{3}}$ and $\sigma_{\mathrm{O}_{3}}^{2}$ calculated from the $\mathrm{O}_{3}$ cross-section spectrum at $228 \mathrm{~K}$. The correction for the Ring effect is based on the technique outlined by Vountas et al. (1998). This technique involves a PCA of a set of Ring spectra, calculated for a range of solar zenith angles. The first two of the resulting eigenvectors appear to accurately describe the Ring spectra, with the first eigenvector representing the filling-in of Fraunhofer lines and the second mostly representing the filling-in of gas absorption features. In the retrieval algorithm, these vectors are determined by orthogonalizing two Ring spectra, calculated by LIDORT-RRS (Spurr et al., 2008), a version of LIDORT accounting for rotational Raman scattering, for a low SZA $\left(20^{\circ}\right)$ and a high SZA $\left(87^{\circ}\right)$, respectively.

\section{Wavelength calibration and convolution to TROPOMI resolution}

The quality of a DOAS fit critically depends on the accuracy of the alignment between the earthshine radiance spectrum, the reference spectrum and the cross sections. Although the level $1 \mathrm{~b}$ will contain a spectral assignment, an additional spectral calibration is part of the $\mathrm{SO}_{2}$ algorithm. Moreover, the DOAS spectral analysis also includes the fit of shift and stretch of radiance spectra because the TROPOMI spectral registration will differ from one ground pixel to another, e.g., due to thermal variations over the orbit as well as due to inhomogeneous filling of the slit in flight direction.

The wavelength registration of the reference spectrum can be fine-tuned by means of a calibration procedure making use of the solar Fraunhofer lines. To this end, a reference solar atlas, $E_{\mathrm{s}}$, accurate in absolute vacuum wavelength to better than $0.001 \mathrm{~nm}$ (Chance and Kurucz, 2010) is degraded at the resolution of the instrument, through convolution by the TROPOMI instrumental slit function.

Using a nonlinear least-squares approach, the shift $\left(\Delta_{i}\right)$ between the reference solar atlas and the TROPOMI irradiance is determined in a set of equally spaced sub-intervals covering a spectral range large enough to encompass all relevant fitting intervals. The shift is derived according to the following equation:

$E_{0}(\lambda)=E_{\mathrm{s}}\left(\lambda-\Delta_{i}\right)$,

where $E_{\mathrm{s}}$ is the solar spectrum convolved at the resolution of the instrument and $\Delta_{i}$ is the shift in sub-interval $i$. A polynomial is then fitted through the individual points in order to reconstruct an accurate wavelength calibration $\Delta(\lambda)$ for the complete analysis interval. Note that this approach allows one to compensate for stretch and shift errors in the original wavelength assignment.

In the case of TROPOMI, the procedure is complicated by the fact that such calibrations must be performed (and stored) for each separate spectral field on the CCD detector array. Indeed, due to the imperfect characteristics of the imaging optics, each row of the TROPOMI instrument must be considered a separate spectrometer for analysis purposes.

In a subsequent step of the processing, the absorption cross sections of the different trace gases must be convolved with the instrumental slit function. The baseline approach is to use slit functions determined as part of the TROPOMI key data. Slit functions are delivered for each binned spectrum and as a function of wavelength. Note that an additional feature of the prototype algorithm allows for an effective slit function of known line shape to be dynamically fitted (e.g., asymmetric Gaussian). This can be used for verification and monitoring purpose during commissioning and later on during the mission.

More specifically, wavelength calibrations are made for each TROPOMI orbit as follows:

1. The TROPOMI irradiances (one for each row of the CCD) are calibrated in wavelength over the $310-390 \mathrm{~nm}$ wavelength range, using 10 sub-windows.

2. The earthshine radiances and the absorption cross sections are interpolated (cubic spline interpolation) on the calibrated wavelength grid, prior to the DOAS analysis.

3. During spectral fitting, shift and stretch parameters are further derived to align radiance and irradiance spectra. 
Table 3. Criteria for selecting alternative fitting windows.

\begin{tabular}{llll}
\hline Window number & w1 & w2 & w3 \\
\hline Wavelength range & $312-326 \mathrm{~nm}$ & $325-335 \mathrm{~nm}$ & $360-390 \mathrm{~nm}$ \\
Derived slant column & S1 & S2 & S3 \\
Application & Baseline for & S1 >15DU & S2 250 DU \\
& every pixel & and S2 >S1 & and S3>S2 \\
\hline
\end{tabular}

The reference wavelength grid used in the DOAS procedure is the (optimized) grid of the TROPOMI solar irradiance.

\section{Spike removal algorithm}

A method to remove individual hot pixels or detector pixels affected by the South Atlantic Anomaly has been presented for $\mathrm{NO}_{2}$ retrievals in Richter et al. (2011). Often only a few individual detector pixels are affected, and in these cases, it is possible to identify and remove the noisy points from the fit. However, as the amplitude of the distortion is usually only of the order of a few percent or less, it cannot always be found in the highly structured spectra themselves. Higher sensitivity for spikes can be achieved by analyzing the residual of the fit where the contribution of the Fraunhofer lines, scattering, and absorption is already removed.

When the residual for a single detector pixel exceeds the average residual of all detector pixels by a chosen threshold ratio (the tolerance factor), the pixel is excluded from the analysis, in an iterative process. This procedure is repeated until no further outliers are identified, or until the maximum number of iterations is reached (here fixed to 3 ). This is especially important to handle the degradation of 2-D detector arrays such as OMI or TROPOMI. However, this improvement of the algorithm has a non-negligible impact on the time of processing. At the time of writing, the exact values for the tolerance factor and maximum number of iterations of the spike removal procedure are difficult to ascertain and will only be known during operations. To assess the impact on the processing time, test retrievals have been done on OMI spectra using a tolerance factor of 5 and a limit of three iterations (this could be relaxed), leading to an increase in processing time by a factor of 1.5 .

\section{Fitting window selection}

The implementation of the multiple-fitting-window retrieval requires selection criteria for the transition from one window to another. These criteria are based on the measured $\mathrm{SO}_{2}$ slant columns. As a baseline, the $\mathrm{SO}_{2} \mathrm{SCD}$ in the $312-$ $326 \mathrm{~nm}$ window will be retrieved for each satellite pixel. When the resulting value exceeds a certain criterion, the slant column retrieval is taken from an alternative window. As part of the algorithm development and during the verification exercise (Sect. 4), closed-loop retrievals have been performed
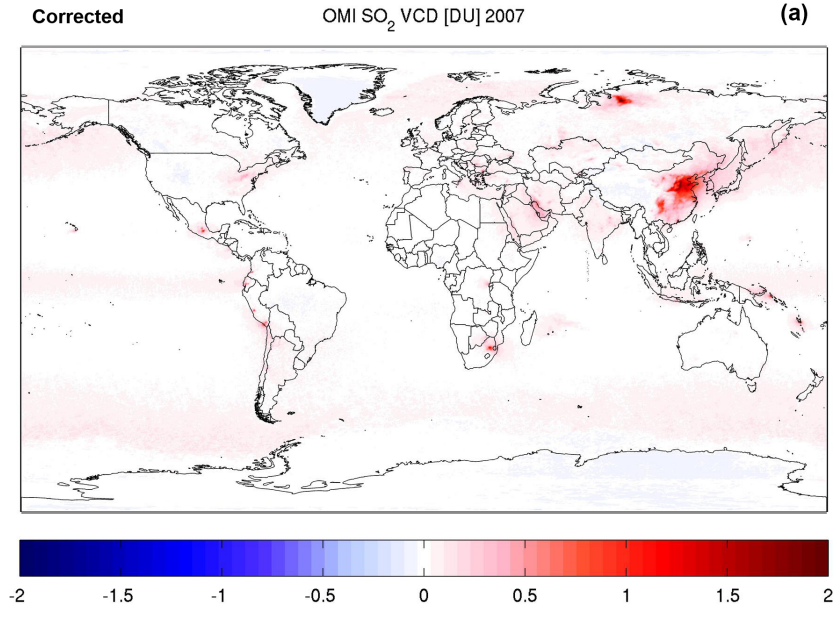

Uncorrected

(b)

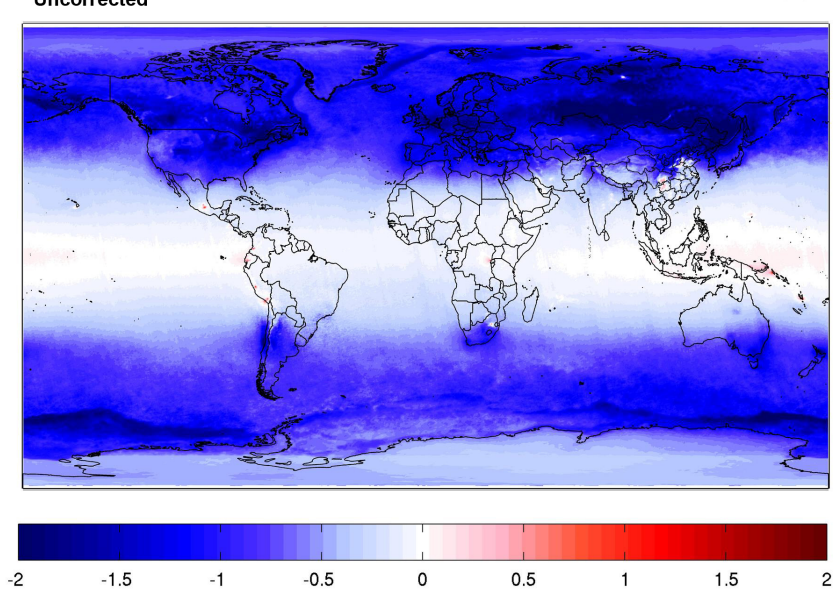

Figure 4. OMI $\mathrm{SO}_{2}$ vertical columns (DU) averaged for the year 2007 (top) with and (bottom) without background correction. Only clear-sky pixels (cloud fraction lower than $30 \%$ ) have been kept. AMFs calculated from $\mathrm{SO}_{2}$ profiles from the IMAGES global model are applied to the slant columns (Theys et al., 2015).

and application of the algorithm to real data from the GOME2 and OMI instruments lead to threshold values and criteria as given in Table 3.

\subsubsection{Offset correction}

When applying the algorithm to OMI and GOME-2 data, across-track/viewing-angle-dependent residuals of $\mathrm{SO}_{2}$ were found over clean areas and negative $\mathrm{SO}_{2} \mathrm{SCDs}$ are found at high SZA which need to be corrected (note that this is a common problem of most algorithms to retrieve $\mathrm{SO}_{2}$ from space UV sensors). A background correction scheme was found mostly necessary for the $\mathrm{SO}_{2}$ slant columns retrieved in the baseline fitting window. The adopted correction scheme depends on across-track position and measured $\mathrm{O}_{3}$ slant column as described below. 
The correction is based on a parameterization of the background values that are then subtracted from the measurements. The scheme first removes pixels with high SZA $\left(>70^{\circ}\right)$ or SCDs larger than $1.5 \mathrm{DU}$ (measurements with presumably real $\mathrm{SO}_{2}$ ) and then calculates the offset correction by averaging the $\mathrm{SO}_{2}$ data on an ozone slant column grid (bins of $75 \mathrm{DU}$ ). This is done independently for each acrosstrack position and hemisphere, and the correction makes use of measurements averaged over a time period of 2 weeks preceding the measurement of interest (to improve the statistics and minimize the impact of a possible extended volcanic $\mathrm{SO}_{2}$ plume on the averaged values).

It should be noted that the $\mathrm{O}_{3}$ slant column is dependent on the wavelength when applying the approach of Pukîte et al. (2010):

$\operatorname{SCD}(\lambda)=\operatorname{SCD}_{T 1}+\operatorname{SCD}_{T 2}+\lambda \mathrm{SCD}_{\lambda}+\sigma_{s}(\lambda) \mathrm{SCD}_{s}$.

$\mathrm{SCD}_{T 1}$ and $\mathrm{SCD}_{T 2}$ are the retrieved ozone slant columns corresponding to the ozone cross sections at two temperatures $(T 1, T 2)$ included in the fit. $\mathrm{SCD}_{\lambda}$ and $\mathrm{SCD}_{s}$ are the retrieved parameters for the two pseudo-cross sections $\lambda \cdot \sigma_{s}$ and $\sigma_{s}^{2}$ ( $\sigma_{s}$ being the $\mathrm{O}_{3}$ cross section at $T 1$ ). In order to apply the background correction, the $\mathrm{O}_{3}$ slant column expression (Eq. 4) is evaluated at $313 \mathrm{~nm}$ (read below).

An example of the effect of the background correction is shown in Fig. 4 for OMI. One can see that after correction (top panel) the retrievals show smooth/unstriped results and values close to zero outside the polluted areas. In some regions (in particular at high latitudes), residual columns can be found, but are generally lower than $0.2 \mathrm{DU}$.

For the two additional fitting windows, residual $\mathrm{SO}_{2} \mathrm{lev}-$ els are relatively small in comparison to the column amounts expected to be retrieved in these windows. However, simplified background corrections are also applied to the alternative windows: the offset corrections use parameterizations of the background slant columns based on latitude (bins of $5^{\circ}$ ), cross-track position and time (2-week moving averages as for the baseline window). To avoid contamination by strong volcanic eruptions, only the pixels are kept with SCD less than 50 and 250 DU for the fitting windows $325-335$ and 360$390 \mathrm{~nm}$, respectively.

It should be noted that the background corrections do not imply saving 2 weeks of $\mathrm{SO}_{2} \mathrm{~L} 2$ data in intermediate products, but only the averaged values $\left(\Sigma_{i=1}, N \mathrm{SCD}_{i} / \mathrm{N}\right)$ over the predefined working grids (note: the numerators $\Sigma_{i=1}, N$ $\mathrm{SCD}_{i}$ and denominators $N$ are stored separately).

This background correction is well suited for the case of a 2-D-detector array such as TROPOMI, for which acrosstrack striping can possibly arise due to imperfect crosscalibration and different dead/hot pixel masks for the CCD detector regions. This instrumental effect can also be found for scanning spectrometers, but since these instruments only have one single detector, such errors do not appear as stripes. These different retrieval artifacts can be compensated for (up to a certain extent) using background corrections which depend on the across-track position. All of these corrections are also meant to handle the time-dependent degradation of the instrument. Note that experiences with OMI show that the most efficient method to avoid across-track stripes in the retrievals is to use row-dependent mean radiances as control spectrum in the DOAS fit.

\subsubsection{Air mass factors}

The DOAS method assumes that the retrieved slant column (after appropriate background correction) can be converted into a vertical column using a single air mass factor $M$ (representative of the fitting interval):

$M=\frac{N_{\mathrm{s}}}{N_{\mathrm{v}}}$,

which is determined by radiative transfer calculations with LIDORT version 3.3 (Spurr, 2008). The AMF calculation is based on the formulation of Palmer et al. (2001):

$M=\int m^{\prime}(p) \cdot s(p) \mathrm{d} p$,

with $m^{\prime}=m(p) / C_{\text {temp }}(p)$, where $m(p)$ is the so-called weighting function (WF) or pressure-dependent air mass factor, $C_{\text {temp }}$ is a temperature correction (see Sect. 2.2.3.7) and $s$ is the $\mathrm{SO}_{2}$ normalized a priori mixing ratio profile, as a function of pressure $(p)$.

The AMF calculation assumes Lambertian reflectors for the ground and the clouds and makes use of pre-calculated WF LUTs at 313, 326 and $375 \mathrm{~nm}$ (depending on the fitting window used). Calculating the AMF at these three wavelengths was found to give the best results using closedloop retrievals (see Auxiliary material of Theys et al., 2015). The WF depends on observation geometry (solar zenith angle: SZA; line-of-sight angle: LOS; relative azimuth angle: RAA), total ozone column (TO3), scene albedo (alb), surface pressure $\left(p_{\mathrm{s}}\right)$, cloud top pressure ( $\left.p_{\text {cloud }}\right)$ and effective cloud fraction $\left(f_{\mathrm{eff}}\right)$.

Examples of $\mathrm{SO}_{2}$ weighting functions are displayed in Fig. 5 (as a function of height for illustration purpose) and show the typical variations in the measurement sensitivity as a function of height, wavelength and surface albedo.

The generation of the WF LUT has been done for a large range of physical parameters, listed in Table 4. In practice, the WF for each pixel is computed by linear interpolation of the WF LUT at the a priori profile pressure grid and using the auxiliary data sets described in the following subsections. Linear interpolations are performed along the cosine of solar and viewing angles, relative azimuth angle and surface albedo, while a nearest-neighbor interpolation is performed in surface pressure. In particular, the grid of surface pressure 
Table 4. Physical parameters that define the WF look-up table.

\begin{tabular}{|c|c|c|c|}
\hline Parameter & $\begin{array}{l}\text { Number of } \\
\text { grid points }\end{array}$ & Grid values & Symbol \\
\hline Atmospheric pressure $(\mathrm{hPa})$ & 64 & $\begin{array}{l}\text { 1056.77, 1044.17,1031.72, 1019.41, 1007.26, 995.25, } \\
983.38,971.66,960.07,948.62,937.31,926.14,915.09, \\
904.18,887.87,866.35,845.39,824.87,804.88,785.15, \\
765.68,746.70,728.18,710.12,692.31,674.73,657.60, \\
640.90,624.63,608.58,592.75,577.34,562.32,547.70, \\
522.83,488.67,456.36,425.80,396.93,369.66,343.94, \\
319.68,296.84,275.34,245.99,210.49,179.89,153.74, \\
131.40,104.80,76.59,55.98,40.98,30.08,18.73,8.86, \\
4.31,2.18,1.14,0.51,0.14,0.03,0.01,0.001\end{array}$ & $p_{l}$ \\
\hline $\begin{array}{l}\text { Altitude corresponding to } \\
\text { the atmospheric pressure, } \\
\text { using a US standard atmo- } \\
\text { sphere }(\mathrm{km})\end{array}$ & 64 & $\begin{array}{l}-0.35,-0.25,-0.15,-0.05,0.05,0.15,0.25,0.35, \\
0.45,0.55,0.65,0.75,0.85,0.95,1.10,1.30,1.50,1.70, \\
1.90,2.10,2.30,2.50,2.70,2.90,3.10,3.30,3.50,3.70, \\
3.90,4.10,4.30,4.50,4.70,4.90,5.25,5.75,6.25,6.75, \\
7.25,7.75,8.25,8.75,9.25,9.75,10.50,11.50,12.50, \\
13.50,14.50,16.00,18.00,20.00,22.00,24.00,27.50, \\
32.50,37.50,42.50,47.50,55.00,65.00,75.00,85.00, \\
95.00\end{array}$ & $z_{l}$ \\
\hline Solar zenith angle $\left(^{\circ}\right)$ & 17 & $\begin{array}{l}0,10,20,30,40,45,50,55,60,65,70,72,74,76,78 \\
80,85\end{array}$ & $\theta_{0}$ \\
\hline Line-of-sight angle $\left({ }^{\circ}\right)$ & 10 & $0,10,20,30,40,50,60,65,70,75$ & $\theta$ \\
\hline $\begin{array}{l}\text { Relative azimuth } \\
\text { angle }\left({ }^{\circ}\right)\end{array}$ & 5 & $0,45,90,135,180$ & $\varphi$ \\
\hline Total ozone column (DU) & 4 & $205,295,385,505$ & TO3 \\
\hline Surface albedo & 14 & $\begin{array}{l}0,0.01,0.025,0.05,0.075,0.1,0.15,0.2,0.25,0.30 .4 \\
0.6,0.8,1.0\end{array}$ & $A_{\mathrm{S}}$ \\
\hline $\begin{array}{l}\text { Surface/cloud top pressure } \\
(\mathrm{hPa})\end{array}$ & 17 & $\begin{array}{l}\text { 1063.10, 1037.90, 1013.30, 989.28, 965.83, 920.58, } \\
876.98,834.99,795.01,701.21,616.60,540.48,411.05 \\
308.00,226.99,165.79,121.11\end{array}$ & $p_{\mathrm{s}}$ \\
\hline AMF wavelength & 3 & $313,326,375$ & \\
\hline
\end{tabular}

is very thin near the ground in order to minimize interpolation errors caused by the generally low albedo of ground surfaces. Furthermore, the LUT and model pressures are scaled to the respective surface pressures in order to avoid extrapolations outside the LUT range.

\section{Observation geometry}

The LUT covers the full range of values for solar zenith angles, line-of-sight angles and relative azimuth angles that can be encountered in the TROPOMI measurements. The observation geometry is readily present in the L1b data for each satellite pixel.

\section{Total ozone column}

The measurement sensitivity at $313 \mathrm{~nm}$ is dependent on the total ozone absorption. The LUT covers a range of ozone column values from 200 to 500 DU for a set of typical ozone profiles. The total ozone column is directly available from the operational processing of the S-5P total ozone column product.

\section{Surface albedo}

The albedo value is very important for PBL anthropogenic $\mathrm{SO}_{2}$ but less critical for volcanic $\mathrm{SO}_{2}$ when it is higher in the atmosphere. For the surface albedo dimension, we use the climatological monthly minimum Lambertian equivalent reflector (minLER) data from Kleipool et al. (2008) at $328 \mathrm{~nm}$ for $\mathrm{w} 1$ and $\mathrm{w} 2$, and $376 \mathrm{~m}$ for $\mathrm{w} 3$. This database is based on OMI measurements and has a spatial resolution of $0.5^{\circ} \times 0.5^{\circ}$. Note that other surface reflectance databases with improved spatial resolution (more appropriate for TROPOMI) will likely become available and these data sets will be considered for next algorithmic versions. 

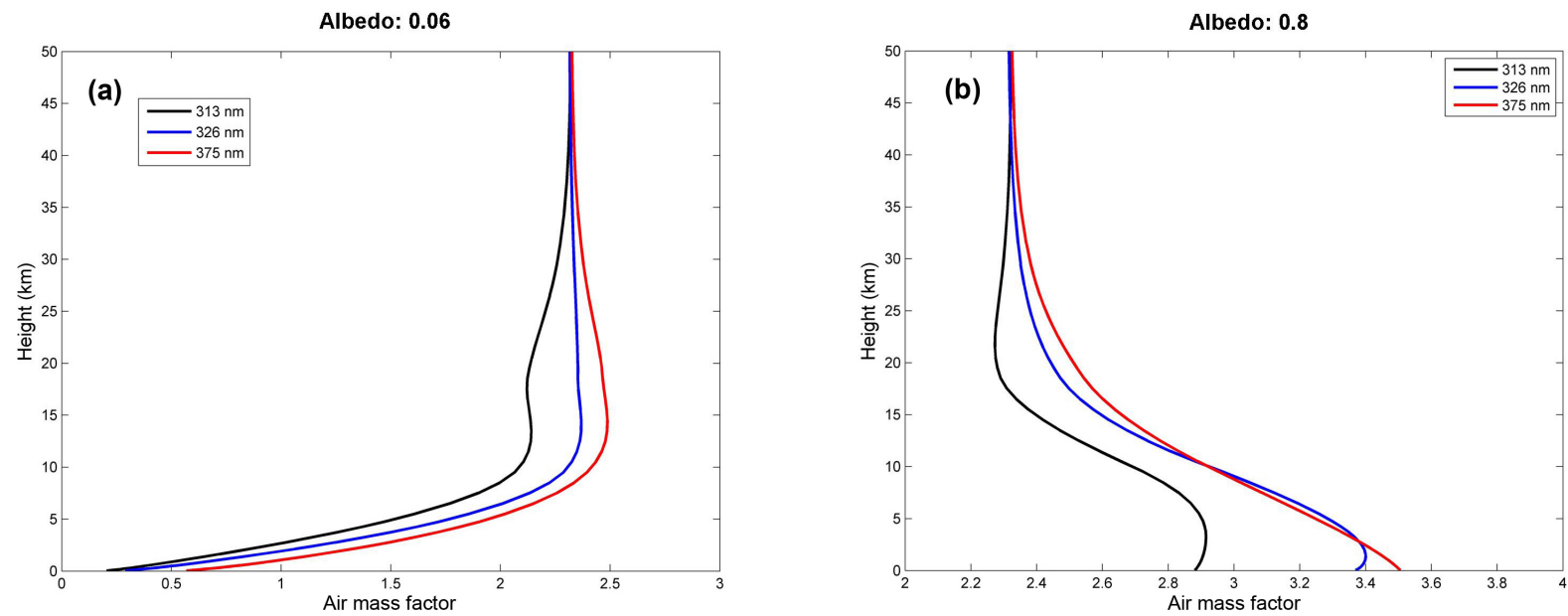

Figure 5. $\mathrm{SO}_{2}$ box AMFs at 313, 326 and $375 \mathrm{~nm}$ for albedo of (a) 0.06 and (b) 0.8 . SZA: $40^{\circ}$; LOS: $10^{\circ}$; RAA: $0^{\circ}$; surface height: $0 \mathrm{~km}$.

\section{Clouds}

The AMF calculations for TROPOMI partly cloudy scenes use the cloud parameters (cloud fraction $f_{\mathrm{c}}$, cloud albedo $A_{\mathrm{c}}$, cloud top pressure ctp) supplied by the nominal S-5P cloud algorithm OCRA/ROCINN in its Clouds as Reflecting Boundaries (CRB) implementation (Loyola et al., 2016). The cloud surface is considered to be a Lambertian reflecting surface and the treatment of clouds is achieved through the independent pixel approximation (IPA; Martin et al., 2002), which considers an inhomogeneous satellite pixel as being composed (as for the radiance intensity) of two independent homogeneous scenes, one completely clear and the other completely cloudy. The weighting function is expressed as

$m(p)=\Phi m_{\text {cloud }}(p)+(1-\Phi) m_{\text {clear }}(p)$,

where $\Phi$ is the intensity-weighted cloud fraction or cloud radiance fraction:

$\Phi=\frac{f_{\text {eff }} I_{\text {cloud }}}{f_{\text {eff }} I_{\text {cloud }}+\left(1-f_{\text {eff }}\right) I_{\text {clear }}}$.

The suffixes "clear" and "cloudy" refer to the WF and intensity calculation corresponding to a fully clear or cloudy pixel, respectively. The WF LUT is therefore accompanied by an intensity LUT with the same input grids. Both LUTs have been generated for a range of cloud cover fractions and cloud top pressures.

Note that the variations in the cloud albedo are directly related to the cloud optical thickness. Strictly speaking, in a Lambertian (reflective) cloud model approach, only thick clouds can be represented. An effective cloud fraction corresponding to an effective cloud albedo of $0.8\left(f_{\text {eff }} \cong f_{c} \frac{A_{c}}{0.8}\right)$ can be defined in order to transform optically thin clouds into equivalent optically thick clouds of reduced extent. Note that in some cases (thick clouds with $A_{\mathrm{c}}>0.8$ ) the effective cloud fraction can be larger than one and the algorithm assumes $f_{\text {eff }}=1$. In such altitude-dependent air mass factor calculations, a single cloud top pressure is assumed within a given viewing scene. For low effective cloud fractions $\left(f_{\text {eff }}\right.$ lower than $10 \%$ ), the current cloud top pressure output is highly unstable and it is therefore reasonable to consider the observation a clear-sky pixel (i.e., the cloud fraction is set to 0 in Eq. 8) in order to avoid unnecessary error propagation through the retrievals, which can be as high as $100 \%$. Moreover, it has been shown recently by Wang et al. (2016) using multi-axis DOAS (MAX-DOAS) observations to validate satellite data that, in the case of elevated aerosol loadings in the PBL (typically leading to apparent $f_{\text {eff }}$ up to $10 \%$ ), it is recommended to apply clear-sky AMFs rather than total AMFs (based on cloud parameters) that presumably correct implicitly for the aerosol effect on the measurement sensitivity.

It should be noted that the formulation of the pressuredependent air mass factor for a partly cloudy pixel implicitly includes a correction for the $\mathrm{SO}_{2}$ column lying below the cloud and therefore not seen by the satellite, the socalled ghost column. Indeed, the total AMF calculation as expressed by Eqs. (6) and (7) assumes the same shape factor and implies an integration of the a priori profile from the top of the atmosphere to the ground, for each fraction of the scene. The ghost column information is thus coming from the a priori profile shapes. For this reason, only observations with moderate cloud fractions ( $f_{\text {eff }}$ lower than $30 \%$ ) are used, unless it can be assumed that the cloud cover is mostly situated below the $\mathrm{SO}_{2}$ layer, i.e., a typical situation for volcanic plumes injected into the upper troposphere or lower stratosphere. 


\section{Surface height}

The surface height $\left(z_{\mathrm{s}}\right)$ is determined for each pixel by interpolating the values of a high-resolution digital elevation map, GMTED2010 (Danielson and Gesch, 2011).

\section{Profile shapes}

It is generally not possible to know at the time of observation what the $\mathrm{SO}_{2}$ vertical profile is and whether the observed $\mathrm{SO}_{2}$ is of volcanic origin or from pollution (or both). Therefore, the algorithm computes four vertical columns for different hypothetical $\mathrm{SO}_{2}$ profiles.

Three box profiles of $1 \mathrm{~km}$ thickness, located in the boundary layer, upper troposphere and lower stratosphere, are used. The first box profile stands for typical conditions of well mixed $\mathrm{SO}_{2}$ (from volcanic or anthropogenic emissions) in the boundary layer, while the upper-troposphere and lowerstratosphere box profiles are representative of volcanic $\mathrm{SO}_{2}$ plumes from effusive and explosive eruptions, respectively.

In order to have more realistic $\mathrm{SO}_{2}$ profiles for polluted scenes, daily forecasts calculated with the global TM5 chemical transport model (Huijnen et al., 2010) will also be used. TM5 will be operated with a spatial resolution of $1^{\circ} \times 1^{\circ}$ in latitude and longitude, and with 34 sigma pressure levels up to $0.1 \mathrm{hPa}$ in the vertical direction. TM5 will use $3 \mathrm{~h}$ meteorological fields from the European Centre for Medium-Range Weather Forecast (ECMWF) operational model (ERA-Interim reanalysis data for reprocessing, and the operational archive for real time applications and forecasts). These fields include global distributions of wind, temperature, surface pressure, humidity, (liquid and ice) water content, and precipitation. A more detailed description of the TM5 model is given at http://tm.knmi.nl/ and by van Geffen et al. (2016).

For the calculation of the air mass factors, the profiles are linearly interpolated in space and time, at the pixel center and S-5P local overpass time, through a model time step of $30 \mathrm{~min}$. For NRT processing, the daily forecast of the TM5 model (located at KNMI) will be ingested by the UPAS operational processor.

To reduce the errors associated to topography and the lower spatial resolution of the model compared to the TROPOMI $7 \mathrm{~km} \times 3.5 \mathrm{~km}$ spatial resolution, the a priori profiles need to be rescaled to effective surface elevation of the satellite pixel. The TM5 surface pressure is converted by applying the hypsometric equation and the assumption that temperature changes linearly with height (Zhou et al., 2009):

$p_{\mathrm{s}}=p_{\mathrm{TM} 5}\left(\frac{T_{\mathrm{TM} 5}}{\left(T_{\mathrm{TM} 5}+\Gamma\left(z_{\mathrm{TM} 5}-z_{\mathrm{s}}\right)\right)}\right)^{-\frac{g}{R \Gamma}}$

where $p_{\mathrm{TM} 5}$ and $T_{\mathrm{TM} 5}$ are the TM5 surface pressure and temperature, $\Gamma=6.5 \mathrm{~K} \mathrm{~km}^{-1}$ the lapse rate, $z_{\mathrm{TM} 5}$ the TM5 terrain height, and $z_{\mathrm{s}}$ surface elevation for the satellite ground pixel. The TM5 $\mathrm{SO}_{2}$ profile is shifted to start at $p_{\mathrm{s}}$ and scaled so that volume mixing ratios are preserved (see Zhou et al., 2009).

\section{Temperature correction}

The $\mathrm{SO}_{2}$ absorption cross sections of Bogumil et al. (2003) show a clear temperature dependence which has an impact on the retrieved $\mathrm{SO}_{2} \mathrm{SCDs}$ depending on the fitting window used. However, only one temperature $(203 \mathrm{~K})$ is used for the DOAS fit, therefore a temperature correction needs to be applied: $\mathrm{SCD}^{\prime}=C_{\text {temp }} . \mathrm{SCD}$. While the $\mathrm{SO}_{2}$ algorithm provides vertical column results for a set of a priori profiles, applying this correction to the slant column is not simple and as a workaround it is preferred to apply the correction directly to the AMFs (or box AMFs to be precise) while keeping the (retrieved) SCD unchanged: $\mathrm{AMF}$ ' $=\mathrm{AMF} / C_{\text {temp }}$. This formulation implicitly assumes that the AMF is not strongly affected by temperature, which is a reasonable approximation (optically thin atmosphere). The correction to be applied requires a temperature profile for each pixel (which is obtained from the TM5 model):

$C_{\text {temp }}=1 /[1-\alpha .(T[K]-203)]$,

where $\alpha$ equals $0.002,0.0038$ and 0 for the fitting windows $312-326,325-335$ and $360-390 \mathrm{~nm}$, respectively. The parameter $\alpha$ has been determined empirically by fitting Eq. (10) through a set of data points (Fig. 6), for each fitting window. Each value in Fig. 6 is the slope of the fitting line between the $\mathrm{SO}_{2}$ differential cross sections at $203 \mathrm{~K}$ vs. the cross section at a given temperature. In the fitting window 360$390 \mathrm{~nm}$, no temperature correction is applied $(\alpha=0)$ because the cross sections are quite uncertain. Moreover, the 360$390 \mathrm{~nm}$ wavelength range is meant for extreme cases (strong volcanic eruptions) for $\mathrm{SO}_{2}$ plumes in the lower stratosphere, where a temperature of $203 \mathrm{~K}$ is a good baseline.

\section{Aerosols}

The presence of aerosol in the observed scene (likely when observing anthropogenic pollution or volcanic events) may affect the quality of the $\mathrm{SO}_{2}$ retrieval (e.g., Yang et al., 2010). No explicit treatment of aerosols (absorbing or not) is foreseen in the algorithm as there is no general and easy way to treat the aerosols effect on the retrieval. At processing time, the aerosol parameters (e.g., extinction profile or single-scattering albedo) are unknown. However, the information on the S-5P UV absorbing aerosol index (AAI) by Zweers (2016) will be included in the $\mathrm{L} 2 \mathrm{SO}_{2}$ files as it gives information to the users on the presence of aerosols for both anthropogenic and volcanic $\mathrm{SO}_{2}$. Nevertheless, the AAI data should be used/interpreted with care. In an offline future version of the $\mathrm{SO}_{2}$ product, absorbing aerosols might be included in the forward model, if reliable information on 

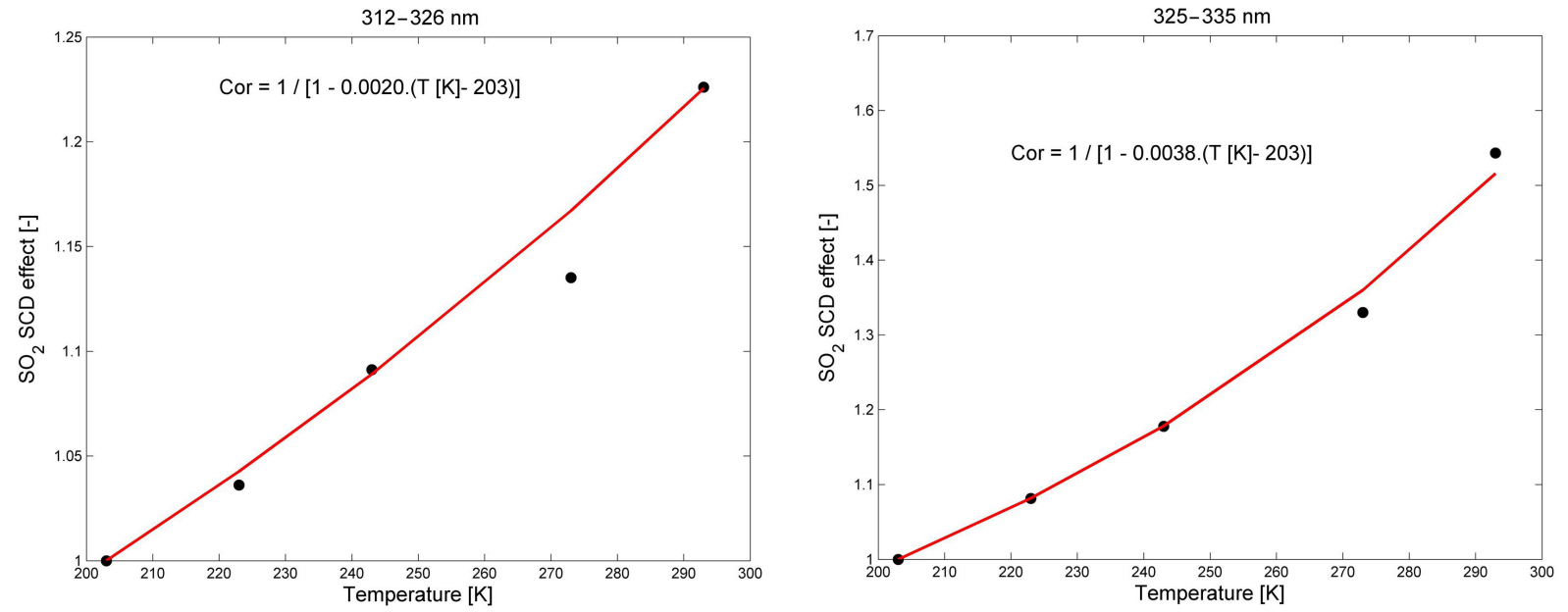

Figure 6. Effect of temperature (relative to $203 \mathrm{~K}$ ) on $\mathrm{SO}_{2}$ retrieved SCD for fitting windows 312-326 (left) and 325-335 nm (right). The red lines show the adopted formulation of $C_{\text {temp }}$ (Eq. 10). Note that, for the $312-326 \mathrm{~nm}$ window, the result at $273 \mathrm{~K}$ has been discarded from the fit as it is seems rather inconsistent with the dependence at other temperatures.

absorbing aerosol can be obtained from the AAI and the S-5P aerosol height product (Sanders and de Haan, 2016).

\section{Error analysis}

\subsection{Introduction}

The total uncertainty (accuracy and precision) on the $\mathrm{SO}_{2}$ columns produced by the algorithm presented in Sect. 2 is composed of many sources of error (see also, e.g., Lee et al., 2009). Several of them are related to the instrument, such as uncertainties due to noise or knowledge of the slit function. These instrumental errors propagate into the uncertainty on the slant column. Other types of error can be considered model errors and are related to the representation of the physics in the algorithm. Examples of model errors are uncertainties on the trace gas absorption cross sections and the treatment of clouds. Model errors can affect the slant column results or the air mass factors.

The total retrieval uncertainty on the $\mathrm{SO}_{2}$ vertical columns can be derived by error propagation, starting from Eq. (1) and if one assumes uncorrelated retrieval steps (Boersma et al., 2004; De Smedt et al., 2008):

$\sigma_{N_{\mathrm{v}}}^{2}=\left(\frac{\sigma_{N_{\mathrm{S}}}}{M}\right)^{2}+\left(\frac{\sigma_{N_{\mathrm{S}}^{\text {back }}}}{M}\right)^{2}+\left(\frac{\left(N_{\mathrm{S}}-N_{\mathrm{S}}^{\mathrm{back}}\right) \sigma_{M}}{M^{2}}\right)^{2}$,

where $\sigma_{\mathrm{Ns}}$ and $\sigma_{\mathrm{Ns}}^{\text {back }}$ are the errors on the slant column $N_{\mathrm{S}}$ and on the background correction $N_{\mathrm{S}}^{\text {back }}$, respectively.
The error analysis is complemented by the total column averaging kernel (AK) as described in Eskes and Boersma (2003):

$\mathrm{AK}(p)=\frac{m^{\prime}(p)}{M}$

( $m^{\prime}$ is the weighting function, Eq. 6), which is often used to characterize the sensitivity of the retrieved column to a change in the true profile.

\subsection{Error components}

The following sections describe and characterize 20 error contributions to the total $\mathrm{SO}_{2}$ vertical column uncertainty. These different error components and corresponding typical values are summarized in Tables 5 and 6 . Note that, at the time of writing, the precise effect of several S-5P-specific error sources are unknown and will be estimated during operations.

A difficulty in the error formulation presented above comes from the fact that it assumes the different error sources/steps of the algorithm to be independent and uncorrelated, which is not strictly valid. For example, the background correction is designed to overcome systematic features/deficiencies of the DOAS slant column fitting, and these two steps cannot be considered independent. Hence, summing up all the corresponding error estimates would lead to overestimated error bars. Therefore, several error sources will be discussed in the following subsections without giving actual values at this point. Their impact is included and described in later subsections.

Another important point to note is that one should also (be able to) discriminate systematic and random components of 
Table 5. Systematic and random error components contributing to the total uncertainty on the $\mathrm{SO}_{2}$ slant column.

\begin{tabular}{|c|c|c|c|c|}
\hline$\#$ & Error source & Type* & Parameter uncertainty & Typical uncertainty on $\mathrm{SO}_{2} \mathrm{SCD}$ \\
\hline 1 & $\begin{array}{l}\mathrm{SO}_{2} \text { absorption } \\
\text { cross section }\end{array}$ & $S$ & $\begin{array}{l}6 \% \text { (window } 1) \\
6 \% \text { (window } 2) \\
\text { unknown (window } 3 \text { ) }\end{array}$ & $6 \%$ \\
\hline 2 & $\mathrm{SO}_{2}$ and $\mathrm{O}_{3}$ absorption & $S \& R$ & & Errors $9 \& 10$ \\
\hline 3 & $\begin{array}{l}\text { Other atmospheric } \\
\text { absorption or interference }\end{array}$ & $\mathrm{S} \& \mathrm{R}$ & & Error 9 \\
\hline 4 & Radiance shot noise & $\mathrm{R}$ & $S / N=800-1000$ & $\begin{array}{l}0.3-0.5 \mathrm{DU} \text { (window } 1 \text { ) } \\
5 \mathrm{DU} \text { (window 2) } \\
60 \mathrm{DU} \text { (window } 3 \text { ) }\end{array}$ \\
\hline 5 & DOAS settings & $\mathrm{S}$ & $1 \mathrm{~nm}$, polynomial order & $\begin{array}{l}<11 \%(\text { window } 1) \\
<6 \%(\text { window } 2) \\
<8 \%(\text { window } 3)\end{array}$ \\
\hline 6 & $\begin{array}{l}\text { Wavelength and } \\
\text { radiometric } \\
\text { calibration }\end{array}$ & $S$ & $\begin{array}{l}\text { Radiometric calibration } \\
\text { Additive errors should } \\
\text { remain below } 2 \%\end{array}$ & $\begin{array}{l}\text { Wavelength calibration and spectral shifts } \\
\text { can be corrected by the } \\
\text { algorithm to less than } 5 \% \text { effect } \\
\text { on the slant column } \\
\text { Intensity offset correction in } \\
\text { principle treats (small) } \\
\text { radiometric calibration errors }\end{array}$ \\
\hline 7 & $\begin{array}{l}\text { Spectral response } \\
\text { function }\end{array}$ & & TBD & $\begin{array}{l}\text { TROPOMI-specific } \\
\text { Expected uncertainty: } 10 \%\end{array}$ \\
\hline 8 & $\begin{array}{l}\text { Other spectral } \\
\text { features }\end{array}$ & & $\begin{array}{l}\text { Strongly dependent } \\
\text { on interfering signal }\end{array}$ & - \\
\hline 9 & $\begin{array}{l}\text { Background } \\
\text { correction }\end{array}$ & S \& R & & $0.2 \mathrm{DU}$ \\
\hline
\end{tabular}

${ }^{*}$ R: random; S: systematic.

a given error source V:

$\sigma_{\mathrm{V}}^{2}=\frac{\sigma_{\mathrm{V}(\text { rand })}^{2}}{n}+\sigma_{\mathrm{V}(\text { syst })}^{2}$,

here $n$ is the number of pixels considered. However, they are hard to separate in practice. Therefore, each of the 20 error contributions are (tentatively) classified as either "random" or "systematic" errors, depending on their tendencies to average out in space/time or not.

\subsubsection{Errors on the slant column}

Error sources that contribute to the total uncertainty on the slant column originate both from instrument characteristics and uncertainties/limitations on the representation of the physics in the DOAS slant column fitting algorithm. For the systematic errors on the slant column, the numbers provided in Table 5 have been determined based on sensitivity tests (using the QDOAS software).

With all effects summed in quadrature, the various contributions are estimated to account for a systematic error of about $20 \%+0.2 \mathrm{DU}$ of the background-corrected slant column $\left(\sigma_{N_{\mathrm{s}}, \mathrm{syst}}=0.2 \times\left(N_{\mathrm{s}}-N_{\mathrm{s}}^{\mathrm{back}}\right)+0.2 \mathrm{DU}\right)$.

For the random component of the slant column errors, the error on the slant columns provided by the DOAS fit is considered (hereafter referred to as SCDE) as it is assumed to be dominated by and representative of the different random sources of error.

\section{Error source 1: $\mathrm{SO}_{2}$ cross section}

Systematic errors on slant columns due to $\mathrm{SO}_{2}$ cross-section uncertainties are estimated to be around $6 \%$ (Vandaele et al., 2009) in window $1(312-326 \mathrm{~nm})$ and window 2 (325$335 \mathrm{~nm}$ ) and unknown in window $3(360-390 \mathrm{~nm})$. In addition, the effect of the temperature on the $\mathrm{SO}_{2}$ cross sections has to be considered as well. Refer to Sect. 3.2.2 for a discussion of this source of error. 
Table 6. Systematic and random error components contributing to the total uncertainty on the $\mathrm{SO}_{2}$ air mass factor.

\begin{tabular}{|c|c|c|c|c|}
\hline \# & Error & Type $^{1}$ & $\begin{array}{l}\text { Parameter } \\
\text { uncertainty }\end{array}$ & Typical uncertainty on the AMF \\
\hline 10 & $\begin{array}{l}\text { AMF wavelength } \\
\text { dependence }\end{array}$ & $S$ & & $10 \%$ \\
\hline 11 & Model atmosphere & $\mathrm{S}$ & $\begin{array}{l}\mathrm{O}_{3} \text { profile } \\
P, T \text { profiles }\end{array}$ & $\begin{array}{l}\sim 5-10 \% \\
\text { small }\end{array}$ \\
\hline 12 & Forward model & $\mathrm{S}$ & $<5 \%$ & $<5 \%$ \\
\hline 13 & Surface albedo ${ }^{2}$ & $S$ & 0.02 & $\begin{array}{l}15 \%(\mathrm{PBL}) \\
5 \%(\mathrm{FT}) \\
1 \%(\mathrm{LS})\end{array}$ \\
\hline 14 & Cloud fraction ${ }^{2}$ & $\mathrm{R}$ & 0.05 & $\begin{array}{l}5 \%(\mathrm{PBL}) \\
15 \%(\mathrm{FT}) \\
1 \%(\mathrm{LS})\end{array}$ \\
\hline 15 & Cloud top pressure ${ }^{2}$ & $\mathrm{R}$ & $50 \mathrm{hPa}$ & $\begin{array}{l}50 \%(\mathrm{PBL}) \\
50 \%(\mathrm{FT}) \\
1 \%(\mathrm{LS})\end{array}$ \\
\hline 16 & Cloud correction & $\mathrm{R}$ & & $<5 \%$ on yearly averaged data \\
\hline 17 & Cloud model & & TBD & \\
\hline 18 & $\mathrm{SO}_{2}$ profile shape & $\mathrm{S}$ & & $\begin{array}{l}\text { anthropogenic } \mathrm{SO}_{2} \\
20-35 \% \\
\text { volcanic } \mathrm{SO}_{2} \\
\text { large (low albedo), } \\
<50 \% \\
\text { (high albedo) }\end{array}$ \\
\hline 19 & Aerosol & $S \& R$ & & $\begin{array}{l}\text { Anthropogenic } \mathrm{SO}_{2} \approx 15 \% \\
\text { (Nowlan et al., 2011). } \\
\text { Volcanic } \mathrm{SO}_{2} \\
\text { (aerosols: ash/sulfate): } \\
\sim 20 \% \\
\text { (Yang et al., 2010) }\end{array}$ \\
\hline 20 & $\begin{array}{l}\text { Temperature } \\
\text { correction }\end{array}$ & $\mathrm{R}$ & & $\sim 5 \%$ \\
\hline
\end{tabular}

${ }^{1}$ R: random; S: systematic. ${ }^{2}$ Effect on the AMF estimated from Fig. 6.

\section{Error source 2: $\mathrm{O}_{3}$ and $\mathrm{SO}_{2}$ absorption}

Nonlinear effects due to $\mathrm{O}_{3}$ absorption are to a large extent accounted for using the Taylor expansion of the $\mathrm{O}_{3}$ optical depth (Pukîţe et al., 2010). Remaining systematic biases are then removed using the background correction; hence, residual systematic features are believed to be small (please read also the discussion on errors 9 and 10). The random component of the slant column error contributes to SCDE.

Nonlinear effects due to $\mathrm{SO}_{2}$ absorption itself (mostly for volcanic plumes) are largely handled by the triple windows retrievals, but - as will be discussed in Sect. 4 - the transition between the different fitting windows is a compromise and there are cases where saturation can still lead to rather large uncertainties. However, those are difficult to assess on a pixel-to-pixel basis.

\section{Error source 3: other atmospheric absorption/interferences}

In some geographical regions, several systematic features in the slant columns remain after the background correction procedure (see discussion on error 9: background correction error) and are attributed to spectral interferences not fully accounted for in the DOAS analysis, such as incomplete treatment of the Ring effect. This effect also has a random component and contributes to the retrieved SCD error (SCDE). 


\section{Error source 4: radiance shot noise}

It has a major contribution to the SCDE and it can be estimated from typical $S / N$ values of S-5P in UV band 3 (8001000 , according to Veefkind et al., 2012). This translates to typical SCD random errors of about $0.3-0.5,5$ and $60 \mathrm{DU}$ for window 1, 2 and 3, respectively. Note that real measurements are needed to consolidate these numbers.

\section{Error source 5: DOAS settings}

Tests on the effect of changing the lower and upper limits of the fitting windows by $1 \mathrm{~nm}$ and the order of the closure polynomial (4 instead of 5) have been performed. Based on a selection of orbits for the Kasatochi eruption (wide range of measured SCDs), the corresponding SCD errors are less than 11,6 and $8 \%$ for window 1,2 and 3 , respectively.

\section{Error source 6: wavelength and radiometric calibration}

Tests on the effect of uncertainties in the wavelength calibration have been performed in the ESA CAMELOT study. The numbers are for a shift of 1/20th of the spectral sampling in the solar spectrum and 1/100th of the spectral sampling in the earthshine spectrum. The shift can be corrected for, but interpolation errors can still lead to a remaining uncertainty of a few percent.

Regarding radiometric calibration, the retrieval result is in principle insensitive to flat (spectrally constant) offsets on the measured radiance because the algorithm includes an intensity offset correction. From the ESA ONTRAQ study it was found that additive error signals should remain within $2 \%$ of the measured spectrum.

\section{Error source 7: spectral response function}

Uncertainties in the S-5P instrumental slit functions can lead to systematic errors on the retrieved $\mathrm{SO}_{2}$ slant columns (to be determined).

\section{Error source 8: other spectral features}

Unknown or untreated instrumental characteristics such as stray light and polarization sensitivity can introduce spectral features that may lead to bias in the retrieved slant column data. To a certain extent these can be prevented by the DOAS polynomial and the intensity offset correction settings, as long as the perturbing signals are a smooth function of wavelength. Conversely, high-frequency spectral structures can have potentially a large impact on $\mathrm{SO}_{2}$ retrievals depending on their amplitude and whether they interfere with $\mathrm{SO}_{2}$ absorption structures. At the time of writing, it is hard to evaluate these measurement errors. Once the instrument will be operating, such measurement errors will be characterized and correct for, either as part of L1b processor or in the form of pseudo-absorption cross sections in the DOAS analysis.
In the ONTRAQ study, testing sinusoidal perturbation signals showed that the effect of spectral features on the retrieval result depends strongly on the frequency of the signal. Additive signals with an amplitude of $0.05 \%$ of the measurement affect the retrieved $\mathrm{SO}_{2}$ slant column by up to $30 \%$. The effect scales more or less linearly with the signal amplitude.

\section{Error source 9: background/destriping correction}

This error source is mostly systematic and important for anthropogenic $\mathrm{SO}_{2}$ or for monitoring degassing volcanoes. Based on OMI and GOME-2 test retrievals, the uncertainty on the background correction is estimated to be $<0.2 \mathrm{DU}$. This value accounts for limitations of the background correction and is compatible with residual slant columns values typically found (after correction) in some clean areas (e.g., above the Sahara), or for a possible contamination by volcanic $\mathrm{SO}_{2}$, after a strong eruption.

\subsubsection{Errors on the air mass factor}

The error estimates on the AMF are listed in Table 6 and are based on simulations and closed-loop tests using the radiative transfer code LIDORT. One can identify two sources of errors on the AMF. First, the adopted LUT approach has limitations in reproducing the radiative transfer in the atmosphere (forward model errors). Secondly, the error on the AMF depends on input parameter uncertainties. This contribution can be broken down into a squared sum of terms (Boersma et al., 2004):

$$
\begin{aligned}
\sigma_{M}^{2} & =\left(\frac{\partial M}{\partial \mathrm{alb}} \cdot \sigma_{\mathrm{alb}}\right)^{2}+\left(\frac{\partial M}{\partial \mathrm{ctp}} \cdot \sigma_{\mathrm{ctp}}\right)^{2} \\
& +\left(\frac{\partial M}{\partial \mathrm{feff}} \cdot \sigma_{\mathrm{feff}}\right)^{2}+\left(\frac{\partial M}{\partial s} \cdot \sigma_{\mathrm{s}}\right)^{2}
\end{aligned}
$$

where $\sigma_{\mathrm{alb}}, \sigma_{\mathrm{ctp}}, \sigma_{\text {feff }}, \sigma_{\mathrm{s}}$ are typical uncertainties on the albedo, cloud top pressure, cloud fraction and profile shape, respectively.

The contribution of each parameter to the total air mass factor error depends on the observation conditions. The air mass factor sensitivities $\left(\frac{\partial M}{\partial \text { parameter }}\right)$, i.e., the air mass factor derivatives with respect to the different input parameters, can be derived for any particular condition of observation using the altitude-dependent AMF LUT, created with LIDORTv3.3, and using the a priori profile shapes. In practice, a LUT of AMF sensitivities has been created using reduced grids from the AMF LUT and a parameterization of the profile shapes based on the profile shape height.

\section{Error source 10: AMF wavelength dependence}

Because of strong atmospheric absorbers (mostly ozone) and scattering processes, the $\mathrm{SO}_{2}$ AMF shows a wavelength dependence. We have conducted sensitivity tests to determine 


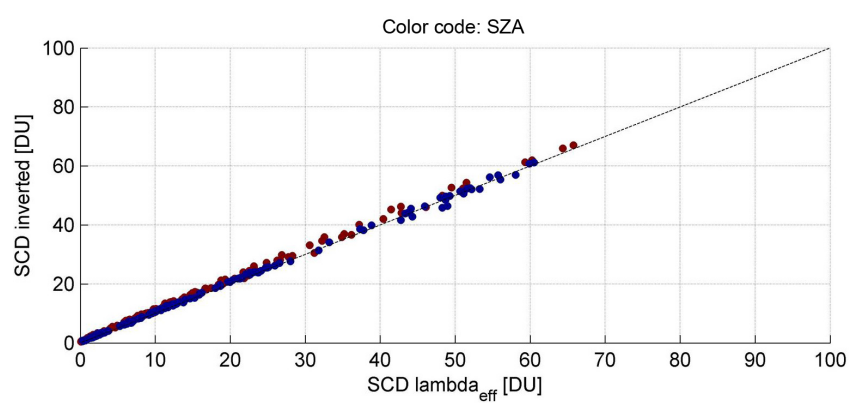

Figure 7. Retrieved $\mathrm{SO}_{2}$ slant columns versus simulated SCDs at a wavelength of $313 \mathrm{~nm}$ from synthetic spectra (SZA: $30,70^{\circ}$ ) in the spectral range $312-326 \mathrm{~nm}$ and for $\mathrm{SO}_{2}$ layers in the boundary layer, upper troposphere and lower stratosphere. The different points correspond to different values for the line-of-sight angle $(0$, $\left.45^{\circ}\right)$, surface albedo $(0.06,0.8)$, surface height $(0,5 \mathrm{~km})$ and total ozone column (350, $500 \mathrm{DU}) . \mathrm{SO}_{2}$ vertical columns as input of the RT simulations are a maximum of $25 \mathrm{DU}$.

the optimal wavelengths for AMF calculations representative of each of the three fitting windows. To do so, synthetic radiances and $\mathrm{SO}_{2} \mathrm{SCDs}$ have been generated using LIDORT for typical observations scenarios and at spectral resolution and sampling compatible with S-5P. The spectra have been analyzed by DOAS and the retrieved SCDs have been compared to the calculated SCDs at different wavelengths. It appears from this exercise that 313,326 and $375 \mathrm{~nm}$ provide the best results, for window 1, 2 and 3, respectively. Figure 7 shows an illustration of these sensitivity tests in the baseline window; an excellent correlation and slope close to 1 is found for the scatter plot of retrieved versus simulated slant columns using an effective wavelength of $313 \mathrm{~nm}$ for the AMF. Overall, for low solar zenith angles, the deviations from the truth are less than $5 \%$ in most cases, except for boundary layer (BL) $\mathrm{SO}_{2}$ at a $1 \mathrm{DU}$ column level and for low-albedo scenes (deviations up to $20 \%$ ). For high solar zenith angles deviations are less than $10 \%$ in most cases, except for $\mathrm{BL} \mathrm{SO}_{2}$ at a 1 DU column level and for low-albedo scenes (underestimation by up to a factor of 2).

\section{Error source 11: model atmosphere}

This error relates to uncertainties in the atmospheric profiles used as input of LIDORT for the weighting function lookup-table calculations.

Although the effect of $\mathrm{O}_{3}$ absorption on the AMF is treated in the algorithm, the $\mathrm{O}_{3}$ profiles used as input of LIDORT are not fully representative of the real profiles and typical errors (including error due to interpolation) of 5-10\% can occur.

A test has been performed by replacing the US standard atmosphere pressure and temperature profiles by high latitude winter profiles and the impact on the results is found to be small.

\section{Error source 12: radiative transfer model}

This error source is believed to be small, less than $5 \%$ (Hendrick et al., 2006; Wagner et al., 2007).

\section{Error source 13: surface albedo}

A typical uncertainty on the albedo is 0.02 (Kleipool et al., 2008). This translates to an error on the air mass factor after multiplication by the slope of the air mass factor as a function of the albedo (Eq. 14) and can be evaluated for each satellite pixel. As an illustration, Fig. 8 shows the expected dependence of the AMF with albedo and also with the cloud conditions. From Fig. 8a, one concludes that the retrievals of $\mathrm{SO}_{2}$ in the $\mathrm{BL}$ are much more sensitive to the exact albedo value than for $\mathrm{SO}_{2}$ higher up in the atmosphere, for this particular example.

More substantial errors can be introduced if the real albedo differs considerably from what is expected, for example in the case of the sudden snowfall or ice cover. The snow/ice cover flag in the L2 file will therefore be useful for such cases.

\section{Error source 14: cloud fraction}

An uncertainty on the cloud fraction of 0.05 is considered. The corresponding AMF error can be estimated through Eq. (14; see Fig. 8b) or by analytic derivation from Eqs. (6)(8).

\section{Error source 15: cloud top pressure}

An uncertainty on the cloud top height of $0.5 \mathrm{~km}(\sim 50 \mathrm{hPa})$ is assumed. The corresponding AMF error can be estimated through Eq. (14). Figure 8c illustrates the typical behavior of signal amplification/shielding for a cloud below/above the $\mathrm{SO}_{2}$ layer. One can see that the error (slope) dramatically increases when the cloud is at a height similar to the $\mathrm{SO}_{2}$ bulk altitude.

\section{Error source 16: cloud correction}

Sensitivity tests showed that applying the independent pixel approximation or assuming cloud-free pixels makes a difference of only $5 \%$ on yearly averaged data (for anthropogenic $\mathrm{BL} \mathrm{SO}_{2} \mathrm{VC}$ with cloud fractions less than $40 \%$ ).

\section{Error source 17: cloud model}

Cloud as layer (CAL) is the baseline of the S-5P cloud algorithm, but a Lambertian equivalent reflector (LER) implementation will be used for $\mathrm{NO}_{2}, \mathrm{SO}_{2}$ and $\mathrm{HCHO}$ retrievals. The error due to the choice of the cloud model will be evaluated during the operational phase. 

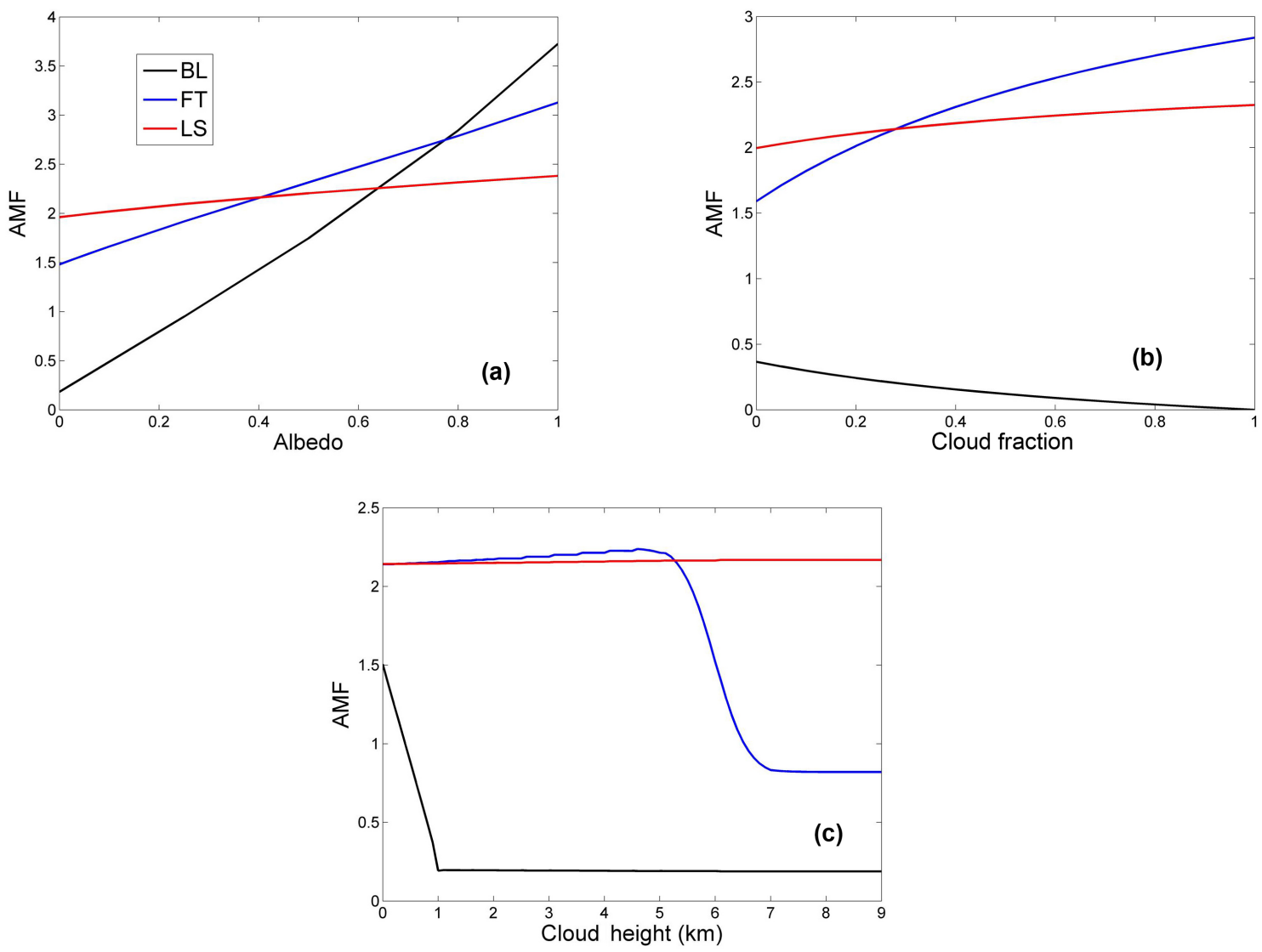

Figure 8. Air mass factors at $313 \mathrm{~nm}$ for $\mathrm{SO}_{2}$ in the boundary layer (BL: 0-1 km), free troposphere and lower stratosphere (FT, LS: Gaussian profiles with maximum height at 6,15 km; FWHM: $1 \mathrm{~km}$ ). Calculations are for $\mathrm{SZA}=40^{\circ}, \mathrm{Los}=10^{\circ}, \mathrm{RAA}=0^{\circ}$ and surface height $=0 \mathrm{~km}$. AMFs are displayed as a function of the (a) albedo for clear-sky conditions, (b) cloud fraction for albedo $=0.06$, cloud albedo $=0.8$ and cloud top height $=2 \mathrm{~km}$ and $(\mathbf{c})$ cloud top height for albedo $=0.06$, cloud albedo $=0.8$ and cloud fraction $=0.3$.

\section{Error source 18: profile shape}

A major source of systematic uncertainty for most $\mathrm{SO}_{2}$ scenes is the shape of the vertical $\mathrm{SO}_{2}$ distribution. The corresponding AMF error can be estimated through Eq. (14) and estimation of uncertainty on the profile shape. Note that vertical columns are provided with their averaging kernels, so that column data might be improved for particular locations by using more accurate $\mathrm{SO}_{2}$ profile shapes based on input from models or observations.

For anthropogenic $\mathrm{SO}_{2}$ under clear-sky conditions, sensitivity tests using a box profile from 0 to $1 \pm 0.5 \mathrm{~km}$ above ground level, or using the different profiles from the CAMELOT study (Levelt et al., 2009), give differences in AMFs in the range of $20-35 \%$. Note that for particular conditions $\mathrm{SO}_{2}$ may also be uplifted above the top of the boundary layer and sometimes reach upper-tropospheric levels (e.g., Clarisse et al., 2011). $\mathrm{SO}_{2}$ weighting functions displayed in Fig. 5 show that the measurement sensitivity is then increased by up to a factor of 3 and therefore constitutes a major source of error.
In the $\mathrm{SO}_{2}$ algorithm, the uncertainty on the profile shape is estimated using one parameter describing the shape of the TM5 profile: the profile height, i.e., the altitude (pressure) below which resides $75 \%$ of the integrated $\mathrm{SO}_{2}$ profile. $\frac{\partial M}{\partial s}$ is approached by $\frac{\partial M}{\partial s_{\mathrm{h}}}$, where $s_{\mathrm{h}}$ is half of the profile height. Relatively small variations in this parameter have a strong impact on the total air mass factors for low-albedo scenes, because altitude-resolved air mass factors decrease strongly in the lower troposphere, where the $\mathrm{SO}_{2}$ profiles peak (see, e.g., Fig. 5).

For volcanic $\mathrm{SO}_{2}$, the effect of the profile shape uncertainty depends on the surface or cloud albedo. For low-albedo scenes (Fig. 5a), if no external information on the $\mathrm{SO}_{2}$ plume height is available, it is a major source of error at all wavelengths. Vertical columns may vary by up to a factor of 5 . For high-albedo scenes (Fig. 5b), the error is less than $50 \%$. It should be noted that these conditions are often encountered for strong eruptions injecting $\mathrm{SO}_{2}$ well above the cloud deck (high reflectivity). Further uncertainty on the retrieved $\mathrm{SO}_{2}$ column may arise if the vertical distribution shows dis- 
tinct layers at different altitudes, due to the different nature of successive phases of the eruption.

In the $\mathrm{SO}_{2}$ algorithm, three $1 \mathrm{~km}$ thick box profiles are used in the AMF calculations, mostly to represent typical volcanic $\mathrm{SO}_{2}$ profiles. The error due to the profile shape uncertainty is estimated by varying the box center levels by $100 \mathrm{hPa}$.

\section{Error source 19: aerosols}

The effect of aerosols on the air mass factors are not explicitly considered in the $\mathrm{SO}_{2}$ retrieval algorithm. To some extent, however, the effect of the non-absorbing part of the aerosol extinction is implicitly included in the cloud correction (Boersma et al., 2004). Indeed, in the presence of aerosols, the cloud detection algorithm is expected to overestimate the cloud fraction, resulting partly in a compensation effect for cases where aerosols and clouds are at similar heights. Absorbing aerosols have a different effect on the air mass factors and can lead to significant errors for high aerosol optical depths (AODs). In the TROPOMI $\mathrm{SO}_{2}$ product, the absorbing aerosol index field can be used to identify observations with elevated absorbing aerosols.

Generally speaking, the effect of aerosols on AMF is highly variable and strongly depends on aerosol properties (AOD, height and size distribution, single-scattering albedo, scattering phase function, etc.). Typical AMFs uncertainties due to aerosols found in the literature are given in Table 6. As aerosols affect cloud fraction, cloud top height and to some extent the albedo database used, correlations between uncertainties on these parameters are to be expected.

\section{Error source 20: temperature correction}

The DOAS scheme uses an $\mathrm{SO}_{2}$ cross section at only one temperature (Bogumil et al., 2003, at $203 \mathrm{~K}$ ), which is in general not representative of the effective temperature corresponding to the $\mathrm{SO}_{2}$ vertical profile. This effect is in principle accounted for by the temperature correction (which is applied in practice to the AMFs; see Sect. 2.2.3.7) but with a certain associated error of $\sim 5 \%$.

\section{Verification}

The $\mathrm{SO}_{2}$ retrieval algorithm presented in Sect. 2, and hereafter referred as "prototype algorithm", has been applied to OMI and GOME-2 spectra. The results have been extensively verified and validated against different satellite and groundbased data sets (e.g., Theys et al., 2015; Fioletov et al., 2016; Wang et al., 2016). Here we report on further scientific verification activities that took place during the ESA S-5P L2WG project.

In addition to the prototype algorithm, a scientific algorithm (referred as "verification algorithm") has been developed in parallel. Both algorithms have been applied to syn- thetic and real (OMI) spectra and results were compared. In this study, we only present and discuss a selection of results (for OMI).

\subsection{Verification algorithm}

The S-5P TROPOMI verification algorithm was developed in close cooperation between the Max Planck Institute for Chemistry (MPIC) in Mainz (Germany) and the Institut für Methodik und Fernerkundung as part of the Deutsches Institut für Luft- und Raumfahrt Oberpfaffenhofen (DLR-IMF). Like the prototype algorithm (PA), the verification algorithm (VA) uses a multiple fitting window DOAS approach to avoid nonlinear effects during the SCD retrieval in the case of high $\mathrm{SO}_{2}$ concentrations in volcanic plumes. However, especially the alternatively used fitting windows differ strongly from the ones used for the PA and are entirely located in the lower UV range:

- 312.1-324 nm (standard retrieval - SR): similar to baseline PA fitting window, ideal for small columns

- 318.6-335.1 nm (medium retrieval - MR): this fitting window is essentially located in between the first and second fitting window of the PA and was mainly introduced to guarantee a smoother transition between the baseline window and the one used for high $\mathrm{SO}_{2}$ concentrations. The differential $\mathrm{SO}_{2}$ spectral features are still about 1 order of magnitude smaller than in the baseline window.

- 323.1-335.1 nm (alternative retrieval - AR): similar to the intermediate fitting window of the PA. This fitting window is used in the case of high $\mathrm{SO}_{2}$ concentrations. Although it is expected that volcanic events with extreme $\mathrm{SO}_{2}$ absorption are still affected by nonlinear absorption in this window, the wavelength range is sufficient for most volcanic events.

Furthermore, the VA selection criteria for the transition from one window to another are not just based on fixed $\mathrm{SO}_{2} \mathrm{SCD}$ thresholds. The algorithm allows for a slow and smooth transition between different fit ranges by linearly decreasing the weight of the former fitting window and at the same time increasing the weight of the following fitting window:

1. for $\mathrm{SO}_{2} \mathrm{SCD} \leq 4 \times 10^{17}$ molec $\mathrm{cm}^{-2}(\approx 15 \mathrm{DU})$ :

$\mathrm{SO}_{2} \mathrm{SCD}=\mathrm{SR}$

2. for $4 \times 10^{17} \mathrm{molec} \mathrm{cm}^{-2}<\mathrm{SO}_{2} \mathrm{SCD}<9 \times 10^{17} \mathrm{molec}$ $\mathrm{cm}^{-2}$ :

$$
\begin{aligned}
\mathrm{SO}_{2} \mathrm{SCD} & =\mathrm{SR} \times\left[1-\frac{\mathrm{SR}}{9 \times 10^{17} \mathrm{molec} \mathrm{cm}^{-2}}\right] \\
& +\mathrm{MR} \times\left[\frac{\mathrm{SR}}{9 \times 10^{17} \mathrm{molec} \mathrm{cm}^{-2}}\right]
\end{aligned}
$$

Atmos. Meas. Tech., 10, 119-153, 2017 
3. for $\mathrm{SO}_{2} \mathrm{SCD} \geq 9 \times 10^{17}$ molec $\mathrm{cm}^{-2}(\approx 33 \mathrm{DU})$ : $\mathrm{SO}_{2} \mathrm{SCD}=\mathrm{MR}$;

4. for $9 \times 10^{17}$ molec $\mathrm{cm}^{-2}<\mathrm{SO}_{2} \mathrm{SCD}<4.6 \times 10^{18}$ molec $\mathrm{cm}^{-2}$ :

$$
\begin{aligned}
\mathrm{SO}_{2} \mathrm{SCD} & =\mathrm{MR} \times\left[1-\frac{\mathrm{MR}}{4.6 \times 10^{18} \mathrm{molec} \mathrm{cm}^{-2}}\right] \\
& +\mathrm{AR} \times\left[\frac{\mathrm{AR}}{4.6 \times 10^{18} \mathrm{molec} \mathrm{cm}^{-2}}\right]
\end{aligned}
$$

5. for $\mathrm{SO}_{2} \mathrm{SCD} \geq 4.6 \times 10^{18}$ molec $\mathrm{cm}^{-2}(\approx 171 \mathrm{DU})$ :

$$
\mathrm{SO}_{2} \mathrm{SCD}=\mathrm{AR} \text {. }
$$

To convert the final $\mathrm{SO}_{2} \mathrm{SCDs}$ into vertical column densities, a single-wavelength AMF for each of the three fitting windows $\left(\mathrm{SO}_{2} \mathrm{SR}, \mathrm{MR}\right.$ and $\left.\mathrm{AR}\right)$ is calculated using the LIDORT LRRS v2.3 (Spurr et al., 2008). The AMF depends on the viewing angles and illumination, surface and cloud conditions as well as on the $\mathrm{O}_{3}$ total column, which is taken from the $\mathrm{O}_{3}$ total column retrieval. A cloudy and clear-sky AMF is calculated using temperature-dependent cross sections for $\mathrm{SO}_{2}$ (Bogumil et al., 2003) and $\mathrm{O}_{3}$ (Brion et al., 1984): $\operatorname{AMF}(\lambda)=\frac{\ln \left(\frac{I_{+} \mathrm{SO}_{2}}{I_{-\mathrm{SO}_{2}}}\right)}{\tau_{\mathrm{SO}_{2}}}$ with $\left(I_{+} \mathrm{SO}_{2}\right)$ and $\left(I_{-\mathrm{SO}_{2}}\right)$ being simulated earthshine spectra with and without including $\mathrm{SO}_{2}$ as a trace gas, respectively. Both AMFs are combined using the cloud fraction information. Like the PA, the VA is calculated for different a priori $\mathrm{SO}_{2}$ profiles (center of mass at 2.5, 6 and $15 \mathrm{~km}$ ) and a temperature correction is applied (see Sect. 2.2.3.7). In contrast to the PA the VA uses Gaussianshaped $\mathrm{SO}_{2}$ profiles with a FWHM of $2.5 \mathrm{~km}$ rather than box profiles as in the PA. This choice, however, has only a minor influence on the AMF.

For further details on the VA, the reader is referred to the S-5P Science Verification Report (available at https:// earth.esa.int/web/sentinel/user-guides/sentinel-5p-tropomi/ document-library/-/asset_publisher/w9Mnd6VPjXlc/ content/sentinel-5p-tropomi-science-verification-report) for more detailed description and results.

\subsection{Verification results}

For the intercomparison, the prototype algorithm and verification algorithm were applied to OMI data for three different $\mathrm{SO}_{2}$ emission scenarios: moderate volcanic $\mathrm{SO}_{2} \mathrm{VCDs}$ on 1 May 2005, caused by the eruption of the Anatahan volcano, elevated anthropogenic $\mathrm{SO}_{2} \mathrm{VCDs}$, on 1 May 2005, from the Norilsk copper smelter (Russia), and strongly enhanced $\mathrm{SO}_{2}$ VCDs, on 8 August 2008, after the massive eruption of Mt. Kasatochi.

In the following, both algorithms use the same assumption of an $\mathrm{SO}_{2}$ plume located at $15 \mathrm{~km}$ altitude for the AMF calculation. Even if this choice is not realistic for some of the presented scenarios, it minimizes the influence of differences in the a priori settings. Main deviations between prototype and verification algorithm are therefore expected to be caused by the usage of different fit windows (determining their sensitivity and fit error) and especially the corresponding transition criteria.

Figure 9 shows the resulting maps of the $\mathrm{SO}_{2} \mathrm{VCD}$ for the VA (upper panels) and PA (lower panels) for the three selected test cases. As can be seen, both algorithms result in similar $\mathrm{SO}_{2}$ VCDs; however, a closer look reveals some differences, such as the maximum VCDs, which are not necessarily appearing at the same locations. For the Anatahan case for instance, the maximum VCD is seen closer to the volcano at the eastern end of the plume for the PA, while it appears to be further downwind for the VA. This effect can be explained by the corresponding fit windows used for both algorithms, which may result in deviating $\mathrm{SO}_{2} \mathrm{VCDs}$, especially for $\mathrm{SO}_{2}$ scenarios where the best choice is difficult to assess. This is illustrated in Fig. 10, showing scatter plots of VA versus PA $\mathrm{SO}_{2}$ VCDs for the three test cases (Anatahan, Norilsk and Kasatochi) color-coded differently depending on the fitting window used for VA (left) and PA (right), respectively. While the PA uses strictly separated results from the individual fit windows, the VA allows a smooth transition whenever resulting $\mathrm{SO}_{2} \mathrm{SCDs}$ are found to be located in between subsequent fit ranges.

For all three test cases, it appears that the PA is less affected by data scattering for low $\mathrm{SO}_{2}$ or $\mathrm{SO}_{2}$ free measurements than the VA. For the shortest UV fit windows, both algorithms mainly agree, but VA VCDs tend to be higher by 10-15\% than the PA VCDs for the Anatahan and Kasatochi measurements but interestingly not for the Norilsk case. For $\mathrm{SO}_{2}$ VCDs around $7 \mathrm{DU}$ the PA seems to be slightly affected by saturation effects in $312-326 \mathrm{~nm}$ window, while VA already makes use of a combined SR/MR SCD. For larger $\mathrm{SO}_{2}$ VCDs ( $>10 \mathrm{DU})$, data sets from both algorithms show an increased scattering, essentially resulting from the more intensive use of fitting windows at longer wavelengths (for which the $\mathrm{SO}_{2}$ absorption is weaker). While it is difficult to conclude which algorithm is closer to the actual $\mathrm{SO}_{2} \mathrm{VCDs}$, the combined fit windows of the VA probably are better suited (in some $\mathrm{SO}_{2}$ column ranges) for such scenarios as the $\mathrm{SO}_{2}$ cross section is generally stronger for lower wavelength $(<325 \mathrm{~nm})$ when compared to the intermediate fit window of the PA.

For extremely high $\mathrm{SO}_{2}$ loadings, i.e., for the Kasatochi plume on 8 August 2008, the DOAS retrievals from PA and VA require all three fit windows to prevent systematic underestimation of the resulting $\mathrm{SO}_{2} \mathrm{SCDs}$ due to nonlinear absorption caused by very high $\mathrm{SO}_{2}$ concentrations within the volcanic plume. Figure 9 (right panel) shows that the $\mathrm{SO}_{2}$ distribution is similar for both algorithms, including the location of the maximum $\mathrm{SO}_{2} \mathrm{VCD}$.

From Fig. 10 (lowest panel), it can be seen that the VA shows higher values for $\mathrm{SO}_{2}$ VCDs $<100 \mathrm{DU}$, for all three fit windows. For very high $\mathrm{SO}_{2} \mathrm{VCDs}$, it seems that the ver- 
(a) Anatahan
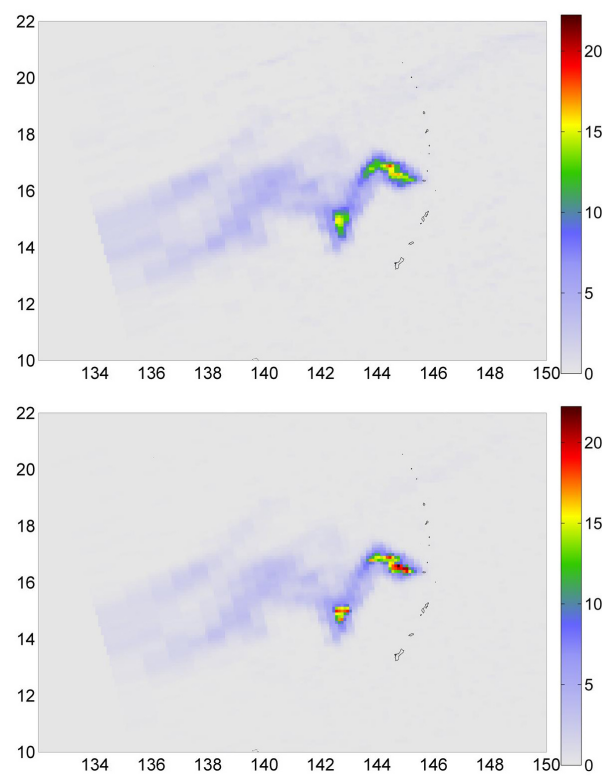

(b) Norilsk
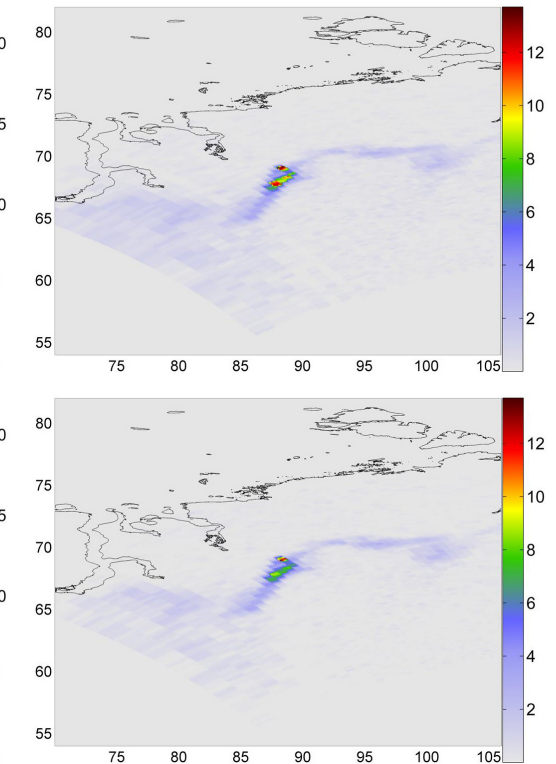

(c) Kasatochi
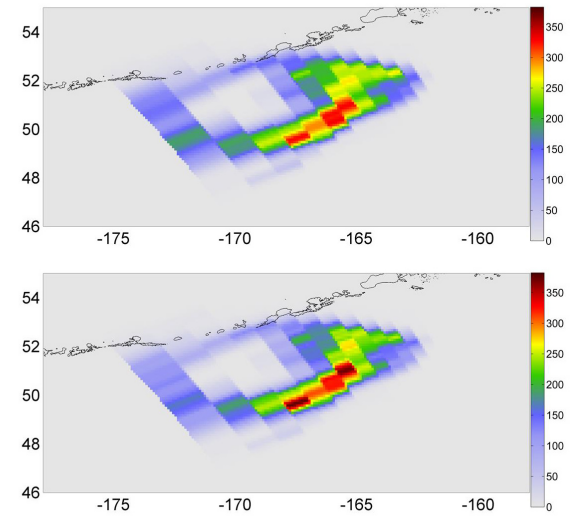

Figure 9. $\mathrm{OMI} \mathrm{SO}_{2} \mathrm{VCD}$ (expressed in DU) for the verification (upper panels) and prototype algorithms (lower panels) for the three selected scenarios: during the Anatahan eruption (left), over the Norilsk copper smelter area (center) and for the volcanic eruption of Kasatochi (right). Note that, for each case, the color bar has been scaled to the maximum $\mathrm{SO}_{2}$ VCD from both algorithms.

ification algorithm is already slightly affected by an underestimation of the $\mathrm{SO}_{2} \mathrm{VCD}$ caused by nonlinear radiative transfer effects in the $\mathrm{SO}_{2}$ AR fit window, while the PA retrievals in the $360-390 \mathrm{~nm}$ fit range are insensitive to saturation effects. We note, however, that the Kasatochi plume also contained significant amounts of volcanic ash and we cannot rule out a possible retrieval effect of volcanic ash on the observed differences between $\mathrm{PA}$ and $\mathrm{VA} \mathrm{SO}_{2}$ results. Finally, we have also investigated other cases with extreme concentrations of $\mathrm{SO}_{2}$, and contrasting results were found compared to the Kasatochi case. For example, on 4 September 2014, PA retrieved up to $260 \mathrm{DU}$ of $\mathrm{SO}_{2}$ during the Icelandic Bárðarbunga fissure eruption, while VA only found 150 DU (not shown). Compared to Kasatochi, we note that this specific scenario is very different as for the plume height (the $\mathrm{SO}_{2}$ plume was typically in the lowermost troposphere $\sim 3 \mathrm{~km}$ a.s.l.) and it is likely to play a role in the discrepancy between PA and VA results.

In summary, we found that the largest differences between prototype and verification algorithms are due to the fitting window transitions and differences of measurement sensitivity of the fitting windows used (all subject differently to nonlinear effects). Verification results have shown that the prototype algorithm produces reasonable results for all the expected scenarios, from modest to extreme $\mathrm{SO}_{2}$ columns, and are therefore adequate for treating the TROPOMI data. In a future processor update, the method could, however, be refined.

\section{Validation of TROPOMI $\mathrm{SO}_{2}$ product}

In this section, we give a brief summary of possibilities (and limitations) to validate the TROPOMI $\mathrm{SO}_{2}$ product with independent measurements.

Generally speaking, the validation of a satellite $\mathrm{SO}_{2}$ column product is a challenge for several reasons, on top of which is the representativeness of the correlative data when compared to the satellite retrievals. Another reason comes from the wide range of $\mathrm{SO}_{2}$ columns in the atmosphere that vary from about $1 \mathrm{DU}$ level for anthropogenic $\mathrm{SO}_{2}$ and lowlevel volcanic degassing to $10-1000$ DU for medium to extreme volcanic explosive eruptions.

The space-borne measurement of anthropogenic $\mathrm{SO}_{2}$ is difficult because of the low column amount and reduced measurement sensitivity close to the surface. The $\mathrm{SO}_{2}$ signal is covered by the competing $\mathrm{O}_{3}$ absorption and the column accuracy is directly affected by the quality of the background correction applied. Among the many parameters of the $\mathrm{SO}_{2}$ retrieval algorithm that affect the results, the $\mathrm{SO}_{2}$ vertical profile shape is of utmost importance for any comparison with correlative data. The $\mathrm{SO}_{2}$ column product accuracy is also directly impacted by the surface albedo used as input for the AMF calculation, the cloud correction/filtering and aerosols. In principle, all these effects will have to be addressed in future validation efforts.

The measurement of volcanic $\mathrm{SO}_{2}$ is facilitated by $\mathrm{SO}_{2}$ columns often larger than for anthropogenic $\mathrm{SO}_{2}$. However, 


\section{(a) Anatahan}
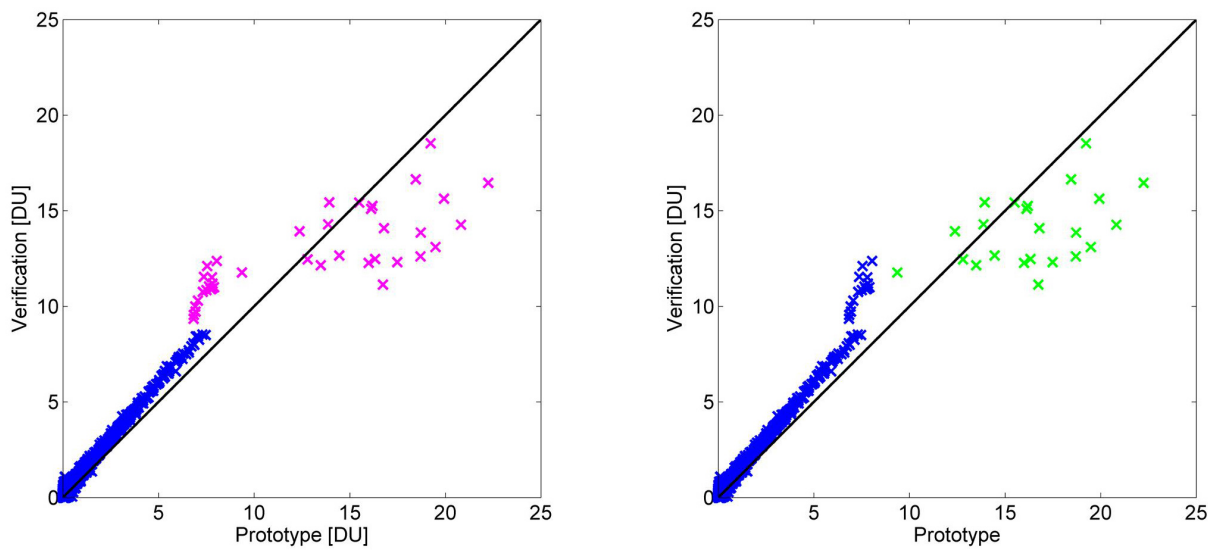

(b) Norilsk
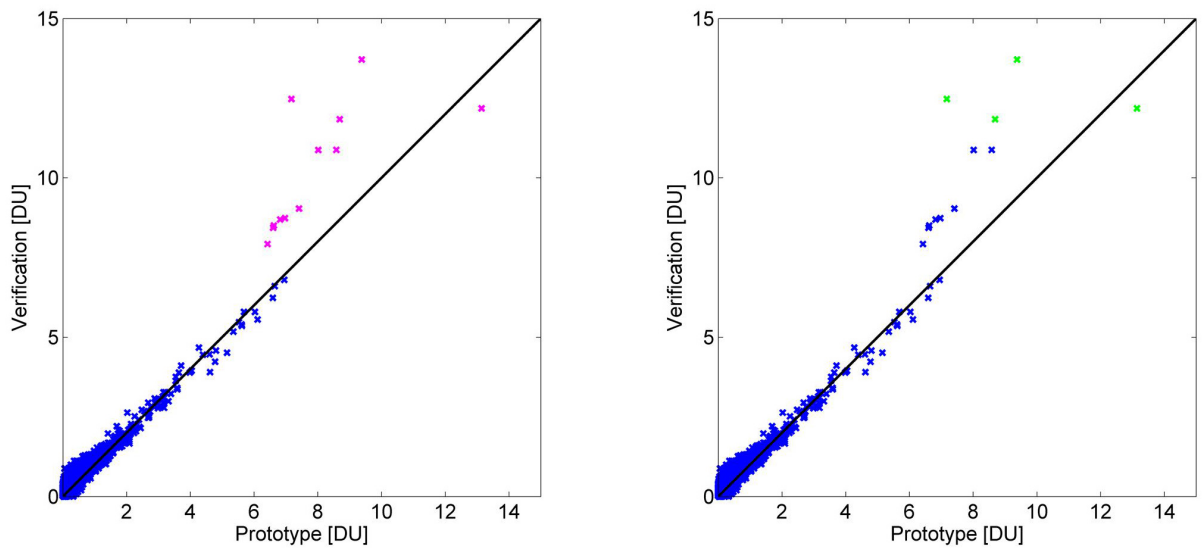

(c) Kasatochi
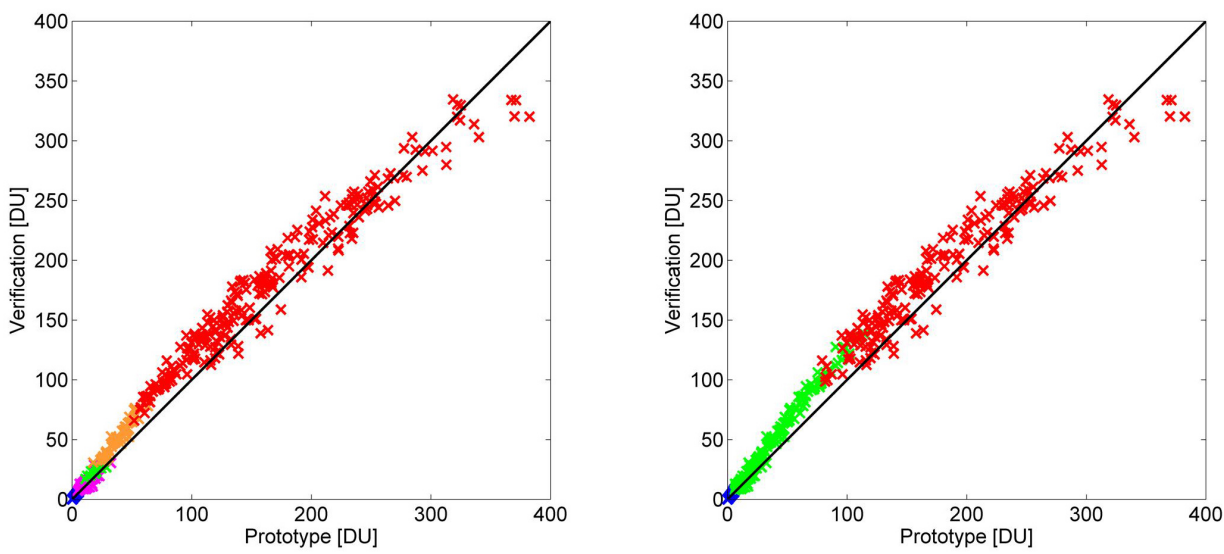

Figure 10. OMI SO 2 VCD (DU) scatter plots for PA ( $x$ axis) and VA ( $y$ axis) for the three test cases: the Anatahan eruption, Norislk anthropogenic emissions and the Kasatochi eruption (from top to bottom). The different fit windows used for both algorithms are colorcoded: VA on left panels (blue: SR; purple: SR/MR; green: MR; orange: MR/AR; red: AR), PA on right panels (blue: 312-326 nm; green: $325-335 \mathrm{~nm}$; red: $360-390 \mathrm{~nm}$ ). For the three scenarios, the prototype and verification algorithms agree fairly well with $r^{2} \sim 0.9$. 
the total $\mathrm{SO}_{2}$ column is strongly dependent on the height of the $\mathrm{SO}_{2}$ plume, which is highly variable and usually unknown. For most volcanoes, there is no ground-based equipment to measure $\mathrm{SO}_{2}$ during an appreciable eruption and even if it is the case, the data are generally difficult to use for validation. For strong eruptions, volcanic plumes are transported over long distances and can be measured by groundbased and aircraft devices, but generally there are only a handful of data sets available and the number of coincidences is rather small.

For both anthropogenic and volcanic $\mathrm{SO}_{2}$ measurements, the vertical distribution of $\mathrm{SO}_{2}$ is a key parameter limiting the product accuracy. If reliable (external) information on the $\mathrm{SO}_{2}$ profile (or profile shape) is available, it is recommended to recalculate the $\mathrm{SO}_{2}$ vertical columns by using this piece of information and the column averaging kernels that can be found in the TROPOMI SO $\mathrm{L}_{2}$ files.

\subsection{Ground-based measurements}

When considering the application of ground-based instruments for the validation of satellite $\mathrm{SO}_{2}$ observations, several types of instruments are to be considered.

Brewer instruments have the advantage to operate as part of a network (http://www.woudc.org), but the retrieved $\mathrm{SO}_{2}$ columns are generally found inaccurate for the validation of anthropogenic $\mathrm{SO}_{2}$. Yet in some cases they might be used for coincidences with volcanic clouds, typically for $\mathrm{SO}_{2} \mathrm{VCDs}$ larger than 5-10 DU. Multi-axis DOAS (MAX-DOAS) or direct-sun DOAS measurements (e.g., from Pandora instruments) can be used to validate satellite $\mathrm{SO}_{2}$ columns from anthropogenic emissions (e.g., Theys et al., 2015; Jin et al., 2016; Wang et al., 2016), but caution must be exercised in the interpretation of the results because realistic $\mathrm{SO}_{2}$ profile shapes must be used by the satellite retrieval scheme. While direct-sun DOAS retrievals are independent of the $\mathrm{SO}_{2}$ profile shape, MAX-DOAS observations carry information on the $\mathrm{SO}_{2}$ vertical distribution, but it is not obvious that the technique is directly applicable to the validation of satellite $\mathrm{SO}_{2}$ retrievals, because the technique is not able to retrieve the full $\mathrm{SO}_{2}$ profile. Another important limitation comes from the fact that ground-based DOAS and satellite instruments have very different fields of view and are therefore probing different air masses. This can cause a large discrepancy between ground-based and satellite measurements in the case of strong horizontal gradients of the $\mathrm{SO}_{2}$ column field. DOAS instruments scanning through volcanic plumes are now routinely measuring volcanic $\mathrm{SO}_{2}$ emissions, as part of the Network for Observation of Volcanic and Atmospheric Change (NOVAC; Galle et al., 2010), for an increasing number of degassing volcanoes. Ongoing research focusses on calculating $\mathrm{SO}_{2}$ fluxes from those measurements and accounting for nontrivial radiative transfer effects (e.g., light dilution; see Kern et al., 2009). NOVAC flux data could be used for comparison with TROPOMI $\mathrm{SO}_{2}$ data, but this requires techniques to convert satellite $\mathrm{SO}_{2}$ vertical column into mass fluxes (see, e.g., Theys et al., 2013, and references therein; Beirle et al., 2014). Similarly, fastsampling UV cameras are becoming increasingly used to measure and invert $\mathrm{SO}_{2}$ fluxes and are also relevant to validate TROPOMI $\mathrm{SO}_{2}$ data over volcanoes or anthropogenic point sources (e.g., power plants). It should be noted, however, that ground-based remote sensing instruments operating nearby $\mathrm{SO}_{2}$ point sources are sensitive to newly emitted $\mathrm{SO}_{2}$ plumes, while a satellite sensor like TROPOMI will measure aged plumes that have been significantly depleted in $\mathrm{SO}_{2}$. While in some cases it is possible to compensate for this effect by estimating the $\mathrm{SO}_{2}$ lifetime, e.g., directly from the space measurements (Beirle et al., 2014), the general situation is that the $\mathrm{SO}_{2}$ loss rate is highly variable (especially in volcanic environments), and this can lead to strong discrepancies when comparing satellite and ground-based $\mathrm{SO}_{2}$ fluxes.

In addition to optical devices, there are also in situ instruments measuring surface $\mathrm{SO}_{2}$ mixing ratios. This type of instrument can only validate surface concentrations, and additional information on the $\mathrm{SO}_{2}$ vertical profile (e.g., from model data) is required to make the link with the satellite retrieved column. However, in situ instruments are being operated for pollution monitoring in populated areas, and allow for extended and long-term comparisons with satellite data (see, e.g., Nowlan et al., 2011).

\subsection{Aircraft and mobile measurements}

Airborne and mobile instruments provide valuable and complementary data for satellite validation.

In the case of volcanic explosive eruptions, satisfactory validation results can be obtained by comparing satellite and fixed ground DOAS measurements of drifting $\mathrm{SO}_{2}$ plumes, as shown by Spinei et al. (2010), but the comparison generally suffers from the small number of coincidences. Dedicated aircraft campaign flights (e.g., Schumann et al., 2011) can in principle improve the situation. Their trajectory can be planned with relative ease to cross sustained eruptive plumes. However, localized high $\mathrm{SO}_{2}$ concentrations may be carried away too quickly to be captured by aircraft or have diluted below the threshold limit for satellite detection before an aircraft can respond. An important database of $\mathrm{SO}_{2}$ aircraft measurements is provided by the CARIBIC/IAGOS project, which exploits automated scientific instruments operating long-distance commercial flights. Measurements of volcanic $\mathrm{SO}_{2}$ during the eruptions of Mt. Kasatochi and Eyjafjallajökull and comparison with satellite data have been reported by Heue et al. (2010, 2011).

An attempt to validate satellite $\mathrm{SO}_{2}$ measurements using a mobile DOAS instrument for a fast moving (stratospheric) volcanic $\mathrm{SO}_{2}$ plume was presented by Carn and Lopez (2011). Although the agreement between both data sets was found reasonable, the comparison was complicated 


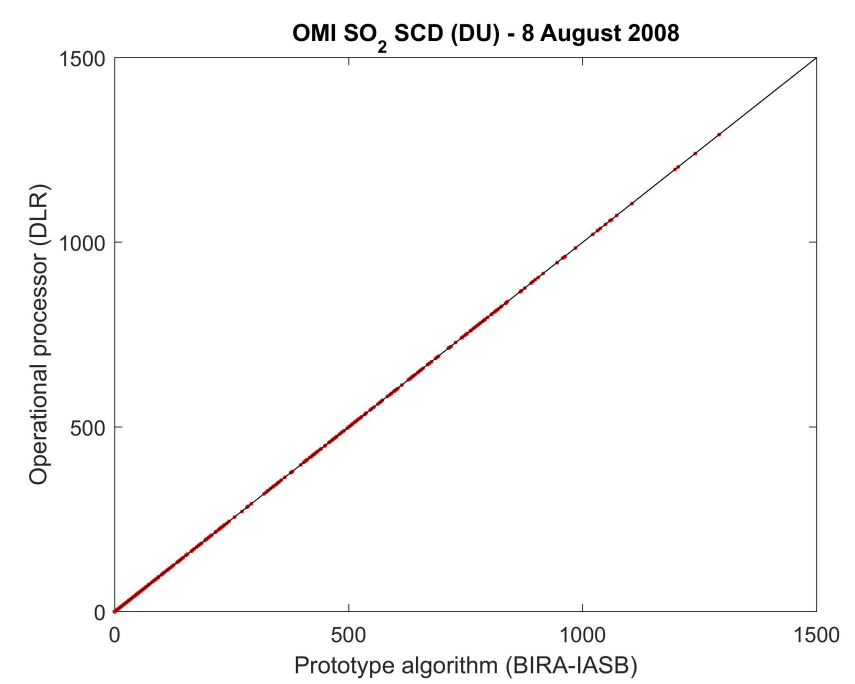

Figure 11. Comparison of $\mathrm{SO}_{2} \mathrm{SCDs}$ between prototype algorithm and operational processor for the OMI test data of 8 August 2008.

by the relatively fast displacement of the volcanic cloud with respect to the ground spectrometer and clear heterogeneity on scales smaller than a satellite pixel. For degassing volcanoes or new fissure eruptions, mobile DOAS traverse measurements under the plume offer unique opportunities to derive volcanic $\mathrm{SO}_{2}$ fluxes that could be used to validate satellite measurements.

For polluted regions, measurements of anthropogenic $\mathrm{SO}_{2}$ by airborne nadir-looking DOAS sensors are able to produce high-spatial-resolution mapping of the $\mathrm{SO}_{2}$ column field (e.g., during the AROMAT campaigns, http:// uv-vis.aeronomie.be/aromat/) that could be used to validate TROPOMI $\mathrm{SO}_{2}$ product or give information on horizontal gradients of the $\mathrm{SO}_{2}$ field (e.g., in combination with coincident mobile DOAS measurements) that would be particularly useful when comparing satellite and MAX-DOAS data (see discussion in Sect. 5.1). Equally important are also limbDOAS or in situ instruments to provide information on the vertical distribution of $\mathrm{SO}_{2}$ which is crucial for satellite validation (e.g., Krotkov et al., 2008).

\subsection{Satellite measurements}

Intercomparison of satellite $\mathrm{SO}_{2}$ measurements generally provides a convenient and easy way to evaluate at a glance the quality of a satellite product, for instance by comparing $\mathrm{SO}_{2}$ maps. Often, it also provides improved statistics and geographical representativeness, but it poses a number of problems because, when different satellite sensors are compared, they have also different overpass times, swaths, spatial resolutions and measurement sensitivities to $\mathrm{SO}_{2}$.

For volcanic $\mathrm{SO}_{2}$, satellite measurements often provide the only data available for the first hours to days after an eruption event and satellite intercomparison is thus the only prac- tical way to assess the quality of the retrievals. To overcome sampling issues mentioned above, intercomparison of $\mathrm{SO}_{2}$ masses integrated over the measured volcanic plume is often performed. For TROPOMI, current satellite instruments will be an important source of data for cross-comparisons. Although non-exhaustive, the following is a list of satellite sensors that could be used: OMI, OMPS, GOME-2 and IASI (MetOp-A, -B, and the forthcoming -C), AIRS, CrIS, VIIRS and MODIS. As mentioned above, the intercomparison of satellite $\mathrm{SO}_{2}$ products is difficult and in this respect the plume altitude is a key factor of the satellite $\mathrm{SO}_{2}$ data accuracy. Comparison of TROPOMI and other satellite $\mathrm{SO}_{2}$ products will benefit not only from the advent of scientific algorithms for the retrieval of $\mathrm{SO}_{2}$ plume heights but also from the use of volcanic plume height observations using space lidar instruments (e.g., CALIOP and the future EarthCare mission).

For both anthropogenic $\mathrm{SO}_{2}$ and volcanic degassing $\mathrm{SO}_{2}$, the satellite UV sensors OMI, GOME-2 and OMPS can be compared to TROPOMI $\mathrm{SO}_{2}$ data by averaging data over certain polluted regions. This procedure will give valuable information on the data quality, but, in some cases, the comparison will suffer from differences in spatial resolution. A more robust and in-depth comparison would be to use different TROPOMI $\mathrm{SO}_{2}$ data sets generated by different retrieval algorithms and investigate the differences in the various retrieval steps (spectral fitting, corrections, radiative transfer simulations, error analysis).

\section{Conclusions}

Based on the heritage from GOME, SCIAMACHY, GOME2 and OMI, a DOAS retrieval algorithm has been developed for the operational retrieval of $\mathrm{SO}_{2}$ vertical columns from TROPOMI level $1 \mathrm{~b}$ measurements in the UV spectral range. Here we describe its main features.

In addition to the traditionally used fitting window of 312 $326 \mathrm{~nm}$, the new algorithm allows for the selection of two additional fitting windows (325-335 and 360-390 nm), reducing the risk of saturation and ensuring accurate $\mathrm{SO}_{2}$ column retrieval even for extreme $\mathrm{SO}_{2}$ concentrations as observed for major volcanic events. The spectral fitting procedure also includes an advanced wavelength calibration scheme and a spectral spike removal algorithm.

After the slant column retrieval, the next step is a background correction, which is empirically based on the $\mathrm{O}_{3}$ slant column (for the baseline fitting window) and across-track position and accounts for possible across-track dependencies and instrumental degradation.

The $\mathrm{SO}_{2}$ slant columns are then converted into vertical columns by means of air mass factor calculations. The latter is based on weighting function look-up tables with dependencies on the viewing geometry, clouds, surface pressure, albedo and ozone and is applied to pre-defined box profiles 
and TM5 CTM forecast profiles. In addition, the algorithm computes DOAS-type averaging kernels and a full error analysis of the retrieved columns.

In this paper we have also presented verification results using an independent algorithm for selected OMI scenes with enhanced $\mathrm{SO}_{2}$ columns. Overall, the prototype algorithm agrees well with the verification algorithm, demonstrating its ability in retrieving accurately medium to very high $\mathrm{SO}_{2}$ columns. We have discussed the advantages and limitations of both prototype and verification algorithms.

Based on the experience with GOME-2 and OMI, the TROPOMI $\mathrm{SO}_{2}$ algorithm is expected to have a comparable level of accuracy. Due to its high signal-to-noise ratio, TROPOMI will be capable of at least achieving comparable retrieval precision as its predecessors but at a much finer spatial resolution of $7 \mathrm{~km} \times 3.5 \mathrm{~km}$ at best. For single measurements, the user requirements for tropospheric $\mathrm{SO}_{2}$ concentrations will not be met, but improved monitoring of strong pollution and volcanic events will be possible by spatial and temporal averaging the increased number of observations of TROPOMI. Nevertheless, it will require significant validation work and here we have discussed some of the inherent challenges for both volcanic and anthropogenic $\mathrm{SO}_{2}$ retrievals. Correlative measurements from ground-based, aircraft/mobile, and satellite instruments will be needed over different regions and various emission scenarios to assess and characterize the quality of TROPOMI $\mathrm{SO}_{2}$ retrievals.
The baseline algorithm presented here, including all its modules (slant column retrieval, background correction, air mass factor calculation and error analysis), has been fully implemented in the S-5P operational processor UPAS by the DLR team. Figure 11 illustrates the status of the implementation for one day of OMI test data, as an example for the slant columns retrievals. A nearly perfect agreement is found between SCD results over 4 orders of magnitude. A similar match between prototype algorithm and operational processor is found for all other retrieval modules.

For more information on the TROPOMI SO $2 ~ \mathrm{~L}_{2}$ data files, the reader is referred to the $\mathrm{S}-5 \mathrm{P} \mathrm{SO}_{2}$ Product User Manual (Pedergnana et al., 2016).

\section{Data availability}

The TROPOMI $\mathrm{SO}_{2}$ retrieval algorithm has been tested on OMI L1 and L2 operational data, publicly available from the NASA Goddard Earth Sciences (GES) Data and Information Services Center (http://disc.sci.gsfc.nasa.gov/ Aura/OMI/omso2.shtml). The static auxiliary datasets used as input of the TROPOMI $\mathrm{SO}_{2}$ retrieval algorithm are publicly available. The links to the data sets are in the references included in Table A2. Other underlying research data are available upon request from Nicolas Theys (theys@aeronomie.be). 
Appendix A: Feasibility, information on data product and ancillary data

\section{High-level data product description}

In addition to the main product results, such as $\mathrm{SO}_{2}$ slant column, vertical column and air mass factor, the level 2 data files will contain several additional parameters and diagnostic information. Table A1 gives a minimum set of data fields that will be present in the level 2 data. A one-orbit $\mathrm{SO}_{2}$ column level 2 file will be about $640 \mathrm{MB}$. More details about the operational level 2 product based on the NetCDF data format and the CF metadata convention are provided in the $\mathrm{SO}_{2}$ Product User Model (Pedergnana et al., 2016).

It should be noted that the averaging kernels are given only for the a priori profiles from the TM5 CTM (to save space). The averaging kernels for the box profiles can be estimated by scaling the provided averaging kernel (corresponding to TM5 profiles): $\mathrm{AK}_{\mathrm{box}}(p)=\mathrm{AK}(p)$. Following the $\mathrm{AK}$ formulation of Eskes and Boersma (2004), the scaling factor is given simply by $\mathrm{AMF}$ ratios: $\mathrm{AMF}_{\mathrm{TM}}$ / $\mathrm{AMF}_{\text {box }}$.

\section{Auxiliary information}

The algorithm relies on several external data sets. These can be either static or dynamic. An overview is given in Tables $\mathrm{A} 2$ and $\mathrm{A} 3$. 
Table A1. List of output fields in the TROPOMI $\mathrm{SO}_{2}$ products. nAlong $\times$ nAcross corresponds to the number of pixels in an orbit along track and across track, respectively; n.u.: no unit.

\begin{tabular}{|c|c|c|c|c|c|}
\hline Name/data & Symbol & Unit & Description & Data type & $\begin{array}{l}\text { Number of entries per } \\
\text { observation }\end{array}$ \\
\hline Date & & n.u. & $\begin{array}{l}\text { Date and time of the measurement YYM- } \\
\text { MDDHHMMSS.MS }\end{array}$ & characters & nAlong \\
\hline Latitudes & lat & degree & Latitudes of the four pixel corners + center & float & $5 \times$ nAlong $\times$ nAcross \\
\hline Longitudes & long & degree & $\begin{array}{l}\text { Longitudes of the four pixel corners }+ \text { cen- } \\
\text { ter }\end{array}$ & float & $5 \times$ nAlong $\times$ nAcross \\
\hline SZA & $\theta_{0}$ & degree & Solar zenith angle & float & nAlong $\times$ nAcross \\
\hline VZA & $\theta$ & degree & Viewing zenith angle & float & nAlong $\times$ nAcross \\
\hline RAA & $\varphi$ & degree & Relative azimuth angle & float & nAlong $\times$ nAcross \\
\hline SCD & $N_{\mathrm{s}}$ & $\mathrm{mol} \mathrm{m}^{-2}$ & $\mathrm{SO}_{2}$ slant column density & float & nAlong $\times$ nAcross \\
\hline SCDcorr & $N_{\mathrm{s}}^{\mathrm{c}}$ & $\mathrm{mol} \mathrm{m}^{-2}$ & $\begin{array}{l}\mathrm{SO}_{2} \text { slant column density background cor- } \\
\text { rected }\end{array}$ & float & nAlong $\times$ nAcross \\
\hline VCD & $N_{\mathrm{V}}$ & $\mathrm{mol} \mathrm{m}^{-2}$ & $\begin{array}{l}\mathrm{SO}_{2} \text { vertical column density } \\
\text { (4 values) }\end{array}$ & float & $4 \times$ nAlong $\times$ nAcross \\
\hline Wdow flag & Wflag & n.u. & Flag for the fitting window used $(1,2,3)$ & integer & nAlong $\times$ nAcross \\
\hline AMF & M & n.u. & Air mass factor (4 values) & float & $4 \times$ nAlong $\times$ nAcross \\
\hline Cloud-free AMF & $M_{\text {clear }}$ & n.u. & Cloud-free air mass factor (4 values) & float & $4 \times$ nAlong $\times$ nAcross \\
\hline Cloudy AMF & $M_{\text {cloud }}$ & n.u. & Fully cloudy air mass factor ( 4 values) & float & $4 \times$ nAlong $\times$ nAcross \\
\hline $\mathrm{CF}$ & $f_{c}$ & n.u. & Cloud fraction & float & nAlong $\times$ nAcross \\
\hline CRF & $\Phi$ & n.u. & Cloud radiance fraction & float & nAlong $\times$ nAcross \\
\hline $\mathrm{CP}$ & $p_{\text {cloud }}$ & $\mathrm{Pa}$ & Cloud top pressure & float & nAlong $\times$ nAcross \\
\hline $\mathrm{CH}$ & $z_{\text {cloud }}$ & $\mathrm{m}$ & Cloud top height & float & nAlong $\times$ nAcross \\
\hline $\mathrm{CA}$ & $A_{\text {cloud }}$ & n.u. & Cloud top albedo & float & nAlong $\times$ nAcross \\
\hline Albedo & $A_{\mathrm{S}}$ & n.u. & Surface albedo & float & nAlong $\times$ nAcross \\
\hline Aerosol index & AAI & n.u. & Absorbing aerosol index & float & nAlong $\times$ nAcross \\
\hline Chi-squared & $\operatorname{chi}^{2}$ & n.u. & Chi-squared of the fit & float & nAlong $\times$ nAcross \\
\hline VCD error & $\sigma N_{\mathrm{V}}$ & $\mathrm{mol} \mathrm{m}^{-2}$ & $\begin{array}{l}\text { Total error on the vertical column (individ- } \\
\text { ual measurement) }\end{array}$ & float & $4 \times$ nAlong $\times$ nAcross \\
\hline SCD random error & $\sigma N_{\text {S_rand }}$ & $\mathrm{mol} \mathrm{m}^{-2}$ & Random error on the slant column & float & nAlong $\times$ nAcross \\
\hline $\begin{array}{l}\text { SCD systematic } \\
\text { error }\end{array}$ & $\sigma N_{\mathrm{S} \_ \text {syst }}$ & $\mathrm{mol} \mathrm{m}^{-2}$ & Systematic error on the slant column & float & nAlong $\times$ nAcross \\
\hline AMF random error & $\sigma M_{\text {rand }}$ & n.u. & $\begin{array}{l}\text { Random error on the air mass factor ( } 4 \text { val- } \\
\text { ues) }\end{array}$ & float & $4 \times$ nAlong $\times$ nAcross \\
\hline $\begin{array}{l}\text { AMF systematic } \\
\text { error }\end{array}$ & $\sigma M_{\text {syst }}$ & n.u. & $\begin{array}{l}\text { Systematic error on the air mass factor ( } 4 \\
\text { values) }\end{array}$ & float & $4 \times$ nAlong $\times$ nAcross \\
\hline Averaging kernel & $\mathrm{AK}$ & n.u. & $\begin{array}{l}\text { Total column averaging kernel (for a priori } \\
\text { profile from CTM) }\end{array}$ & float & $34 \times$ nAlong $\times$ nAcross \\
\hline $\begin{array}{l}\text { Averaging kernel } \\
\text { scalings for box } \\
\text { profiles }\end{array}$ & scaling box & n.u. & $\begin{array}{l}\text { Factors to apply to the averaging kernel } \\
\text { function to obtain the corresponding aver- } \\
\text { aging kernels for the three box profiles }\end{array}$ & float & $3 \times$ nAlong $\times$ nAcross \\
\hline $\mathrm{SO}_{2}$ profile & $n_{a}$ & n.u. & $\begin{array}{l}\text { A priori profile from CTM (volume mixing } \\
\text { ratio) }\end{array}$ & float & $34 \times$ nAlong $\times$ nAcross \\
\hline Surface altitude & $z_{\mathrm{s}}$ & $\mathrm{m}$ & Digital elevation map & float & nAlong $\times$ nAcross \\
\hline Surface pressure & $p_{\mathrm{s}}$ & $\mathrm{Pa}$ & $\begin{array}{l}\text { Effective surface pressure of the satellite } \\
\text { pixel }\end{array}$ & float & nAlong $\times$ nAcross \\
\hline $\begin{array}{l}\text { TM5 level coeffi- } \\
\text { cient a }\end{array}$ & $A_{i}$ & $\mathrm{~Pa}$ & $\begin{array}{l}\text { TM5 pressure level coefficients that ef- } \\
\text { fectively define the mid-layer levels (from } \\
\text { ECMWF) }\end{array}$ & float & 24 \\
\hline $\begin{array}{l}\text { TM5 level coeffi- } \\
\text { cient b }\end{array}$ & $A_{i}$ & n.u. & & float & 24 \\
\hline
\end{tabular}


Table A2. Static auxiliary data for the S-5P $\mathrm{SO}_{2}$ algorithm.

\begin{tabular}{|c|c|c|c|c|c|}
\hline Name/data & Symbol & Unit & Source & $\begin{array}{l}\text { Pre-process } \\
\text { needs }\end{array}$ & Comments \\
\hline \multicolumn{6}{|c|}{ Absorption cross sections } \\
\hline $\mathrm{SO}_{2}$ & $\sigma_{\mathrm{SO}_{2}}$ & $\mathrm{~cm}^{2}$ molec $^{-1}$ & $\begin{array}{l}\text { Bogumil et al. (2003), } \\
\text { 203, 223, 243, 293 K } \\
\text { Hermans et al. (2009), } \\
\text { all temperatures }\end{array}$ & $\begin{array}{l}\text { Convolution at the } \\
\text { instrumental spec- } \\
\text { tral resolution us- } \\
\text { ing the provided } \\
\text { slit function }\end{array}$ & \\
\hline Ozone & $\sigma_{o 3218} \sigma_{o 3243}$ & $\mathrm{~cm}^{2}$ molec $^{-1}$ & $\begin{array}{l}\text { Brion et al. (1998); } \\
218 \text { and } 243 \mathrm{~K}\end{array}$ & & \\
\hline $\mathrm{BrO}$ & $\sigma_{\mathrm{BrO}}$ & $\mathrm{cm}^{2}$ molec $^{-1}$ & $\begin{array}{l}\text { Fleischmann et } \\
\text { al. (2004), } 223 \mathrm{~K}\end{array}$ & & \\
\hline $\mathrm{NO}_{2}$ & $\sigma_{\mathrm{NO}_{2}}$ & $\mathrm{~cm}^{2}$ molec $^{-1}$ & $\begin{array}{l}\text { Vandaele et al. (1998), } \\
220 \mathrm{~K}\end{array}$ & & - \\
\hline $\mathrm{O}_{4}\left(\mathrm{O}_{2}-\mathrm{O}_{2}\right)$ & $\sigma_{\mathrm{O}_{4}}$ & $\mathrm{~cm}^{5}$ molec $^{-2}$ & $\begin{array}{l}\text { Greenblatt et } \\
\text { al. (1990) }\end{array}$ & & \\
\hline $\begin{array}{l}\text { High-resolution } \\
\text { reference solar } \\
\text { spectrum }\end{array}$ & $E_{\mathrm{S}}$ & $\mathrm{W} \mathrm{m}^{-2} \mathrm{~nm}^{-1}$ & $\begin{array}{l}\text { Chance and Kurucz } \\
\text { (2010) }\end{array}$ & - & - \\
\hline Ring effect & $\sigma_{\text {ringev } 1} \sigma_{\text {ringev } 2}$ & $\mathrm{~cm}^{2}$ molec $^{-1}$ & $\begin{array}{l}\text { Two Ring cross sec- } \\
\text { tions generated inter- } \\
\text { nally }\end{array}$ & $\begin{array}{l}\text { A high-resolution } \\
\text { reference solar } \\
\text { spectrum and } \\
\text { the instrument } \\
\text { slit function are } \\
\text { needed to generate } \\
\text { the data set }\end{array}$ & $\begin{array}{l}\text { Calculated in an } \\
\text { ozone containing } \\
\text { atmosphere for low } \\
\text { and high SZA, us- } \\
\text { ing LIDORT_RRS } \\
\text { (Spurr et al., } \\
\text { 2008) and a stan- } \\
\text { dard atmosphere } \\
\text { (CAMELOT Euro- } \\
\text { pean Pollution } \\
\text { atmospheric } \\
\text { profile) }\end{array}$ \\
\hline $\begin{array}{l}\text { Nonlinear } \quad \mathrm{O}_{3} \\
\text { absorption } \\
\text { effect }\end{array}$ & $\sigma_{o 3 s q}$ & $\begin{array}{l}\mathrm{nm} \mathrm{cm}^{2} \mathrm{molec}^{-} \\
\mathrm{cm}^{4} \mathrm{molec}^{-2}\end{array}$ & $\begin{array}{lr}1 & \text { Two pseudo-cross } \\
\text { sections } & \text { generated } \\
\text { internally } & \end{array}$ & $\begin{array}{l}\text { The } \mathrm{O}_{3} \text { cross } \\
\text { section at } 218 \mathrm{~K} \text { is } \\
\text { needed }\end{array}$ & $\begin{array}{l}\text { Calculated from } \\
\text { the Taylor } \\
\text { expansion of the } \\
\text { wavelength and } \\
\text { the } \mathrm{O}_{3} \text { optical } \\
\text { depth (Pukīte et al., } \\
\text { 2010) }\end{array}$ \\
\hline $\begin{array}{l}\text { Instrument slit } \\
\text { function }\end{array}$ & SF & n.u. & $\begin{array}{l}\text { Slit function by } \\
\text { wavelength/detector }\end{array}$ & - & $\begin{array}{l}\text { Values between } \\
300 \text { and } 400 \mathrm{~nm}\end{array}$ \\
\hline Surface albedo & $A_{\mathrm{S}}$ & n.u. & $\begin{array}{l}\text { OMI-based monthly } \\
\text { minimum LER (up- } \\
\text { date of Kleipool et al., } \\
\text { 2008) }\end{array}$ & - & \\
\hline $\begin{array}{l}\text { Digital elevation } \\
\text { map }\end{array}$ & $z_{\mathrm{s}}$ & $\mathrm{m}$ & $\begin{array}{l}\text { GMTED2010 } \\
\text { (Danielson et al., } \\
\text { 2011) }\end{array}$ & & $\begin{array}{l}\text { Average over the } \\
\text { ground pixel area. }\end{array}$ \\
\hline
\end{tabular}


Table A2. Continued.

\begin{tabular}{|c|c|c|c|c|c|}
\hline Name/data & Symbol & Unit & Source & $\begin{array}{l}\text { Pre-process } \\
\text { needs }\end{array}$ & Comments \\
\hline $\mathrm{SO}_{2}$ profile & $n_{a}$ & n.u. & $\begin{array}{l}\text { One-kilometer-thick box profiles, } \\
\text { with three different peak altitudes, } \\
\text { representing different altitude } \\
\text { regimes: } \\
\text { boundary layer: from the surface al- } \\
\text { titude to } 1 \mathrm{~km} \text { above it; } \\
\text { free troposphere: centered around } \\
7 \mathrm{~km} \text { altitude; } \\
\text { lower stratosphere: centered around } \\
15 \mathrm{~km} \text { altitude } \\
\text { Daily } \mathrm{SO}_{2} \text { profiles forecast from } \\
\text { TM5 }\end{array}$ & - & $\begin{array}{l}\text { TM5 profiles from the } \\
\text { last available day if the } \\
\text { TM5 profiles of the cur- } \\
\text { rent day are not avail- } \\
\text { able }\end{array}$ \\
\hline $\begin{array}{l}\text { Temperature } \\
\text { correction } \\
\text { parameters }\end{array}$ & $\alpha$ & $\mathrm{K}^{-1}$ & Bogumil et al. (2003) & - & - \\
\hline
\end{tabular}


Table A3. Dynamic auxiliary data for the $\mathrm{S}-5 \mathrm{P} \mathrm{SO}_{2}$ algorithm.

\begin{tabular}{|c|c|c|c|c|c|}
\hline Name/data & Symbol & Unit & Source & $\begin{array}{l}\text { Pre-process } \\
\text { needs }\end{array}$ & $\begin{array}{l}\text { Backup if not } \\
\text { available }\end{array}$ \\
\hline $\begin{array}{l}S-5 P \text { level } 1 B \\
\text { Earth radiance }\end{array}$ & $I$ & $\mathrm{~mol} \mathrm{~s}^{-1} \mathrm{~m}^{-2} \mathrm{~nm}^{-1} \mathrm{sr}^{-1}$ & S-5P L1b product & - & No retrieval \\
\hline $\begin{array}{l}\text { S-5P level 1B } \\
\text { sun irradiance }\end{array}$ & $E_{0}$ & $\mathrm{~mol} \mathrm{~s}^{-1} \mathrm{~m}^{-2} \mathrm{~nm}^{-1}$ & S-5P L1b product & $\begin{array}{l}\text { Wavelength recalibrated } \\
\text { using a high-resolution } \\
\text { reference solar spectrum }\end{array}$ & $\begin{array}{l}\text { Use previous } \\
\text { measurement }\end{array}$ \\
\hline $\begin{array}{l}\text { S-5P cloud } \\
\text { fraction }\end{array}$ & $f_{c}$ & n.u. & \multirow{3}{*}{$\begin{array}{l}\text { S-5P operational cloud product } \\
\text { based on a Lambertian cloud } \\
\text { model (Loyola et al., 2016) } \\
\text { UPAS processor }\end{array}$} & \multirow[t]{3}{*}{-} & \multirow{3}{*}{ No retrieval } \\
\hline $\begin{array}{l}\text { S-5P cloud top } \\
\text { pressure }\end{array}$ & $p_{\text {cloud }}$ & $\mathrm{Pa}$ & & & \\
\hline $\begin{array}{l}\text { S-5P cloud top } \\
\text { albedo }\end{array}$ & $A_{\text {cloud }}$ & n.u. & & & \\
\hline $\mathrm{SO}_{2}$ profile & $n_{a}$ & n.u. & $\begin{array}{l}\text { Daily forecast from TM5 } \\
\text { CTM run at KNMI. }\end{array}$ & - & $\begin{array}{l}\text { Use TM5 CTM } \\
\text { profile from last } \\
\text { available day }\end{array}$ \\
\hline $\begin{array}{l}\text { Temperature profile } \\
\text { profile }\end{array}$ & $T$ & $\mathrm{~K}$ & $\begin{array}{l}\text { Daily forecast from TM5 } \\
\text { CTM run at KNMI }\end{array}$ & - & $\begin{array}{l}\text { Use TM5 CTM } \\
\text { profile from last } \\
\text { available day }\end{array}$ \\
\hline $\begin{array}{l}\text { S-5P absorbing } \\
\text { aerosol index }\end{array}$ & AAI & n.u. & $\begin{array}{l}\text { S-5P operational AAI product } \\
\text { (Zweers, 2016) } \\
\text { Used for flagging } \\
\text { KNMI processor }\end{array}$ & - & $\begin{array}{l}\text { Missing } \\
\text { information flag }\end{array}$ \\
\hline Snow/ice flag & & n.u. & $\begin{array}{l}\text { Near-real-time global Ice } \\
\text { and Snow Extent (NISE) } \\
\text { data from NASA }\end{array}$ & - & $\begin{array}{l}\text { Use snow/ } \\
\text { ice climatology }\end{array}$ \\
\hline
\end{tabular}


Table A4. Acronyms and abbreviations.

\begin{tabular}{|c|c|}
\hline AAI & Absorbing aerosol index \\
\hline AK & Averaging kernel \\
\hline AMF & Air mass factor \\
\hline AOD & Aerosol optical depth \\
\hline AR & Alternative retrieval \\
\hline $\mathrm{BrO}$ & Bromine monoxide \\
\hline CAL & Cloud as layer \\
\hline CAMELOT & Composition of the Atmospheric Mission concEpts and SentineL Observation Techniques \\
\hline CAPACITY & Composition of the Atmosphere: Progress to Applications in the user CommunITY \\
\hline $\mathrm{CCD}$ & Charge-coupled device \\
\hline $\mathrm{CRB}$ & Clouds as Reflecting Boundaries \\
\hline CTM & Chemical transport model \\
\hline DOAS & Differential optical absorption spectroscopy \\
\hline DU & Dobson unit $\left(1 \mathrm{DU}=2.6867 \times 10^{16}\right.$ molecules $\left.\mathrm{cm}^{-2}\right)$ \\
\hline ECMWF & European Centre for Medium-Range Weather Forecast \\
\hline ESA & European Space Agency \\
\hline FT & Free troposphere \\
\hline FWHM & Full width at half maximum \\
\hline GMES & Global Monitoring for Environment and Security \\
\hline GOME-2 & Global Ozone Monitoring Experiment-2 \\
\hline $\mathrm{HCHO}$ & Formaldehyde \\
\hline IPA & Independent pixel approximation \\
\hline IR & Infrared \\
\hline L2WG & Level-2 Working Group \\
\hline LER & Lambertian equivalent reflector \\
\hline LIDORT & LInearized Discrete Ordinate Radiative Transfer \\
\hline LOS & Line-of-sight angle \\
\hline LS & Lower stratosphere \\
\hline LUT & Look-up table \\
\hline MAX-DOAS & Multi-axis DOAS \\
\hline MR & Medium retrieval \\
\hline $\mathrm{NO}_{2}$ & Nitrogen dioxide \\
\hline NOVAC & Network for Observation of Volcanic and Atmospheric Change \\
\hline NRT & Near-real time \\
\hline OCRA & Optical Cloud Recognition Algorithm \\
\hline $\mathrm{O}_{3}$ & Ozone \\
\hline OMI & Ozone Monitoring Instrument \\
\hline OMPS & Ozone Mapping Profiler Suite \\
\hline PA & Prototype algorithm \\
\hline (P)BL & Planetary boundary layer \\
\hline PCA & Principal component analysis \\
\hline ROCINN & Retrieval Of Cloud Information using Neural Networks \\
\hline RRS & Rotational Raman scattering \\
\hline RTM & Radiative transfer model \\
\hline RAA & Relative azimuth angle \\
\hline S-5P & Sentinel-5 Precursor \\
\hline SCIAMACHY & SCanning Imaging Absorption spectroMeter for Atmospheric ChartograpHY \\
\hline SCD & Slant column density \\
\hline SCDE & Slant column density error \\
\hline$S / N$ & Signal-to-noise ratio \\
\hline $\mathrm{SO}_{2}$ & Sulfur dioxide \\
\hline SR & Standard retrieval \\
\hline SWIR & Shortwave infrared \\
\hline SZA & Solar zenith angle \\
\hline TOMS & Total Ozone Mapping Spectrometer \\
\hline TROPOMI & Tropospheric Monitoring Instrument \\
\hline UPAS & Universal Processor for UV/VIS Atmospheric Spectrometers \\
\hline UV & Ultraviolet \\
\hline VA & Verification algorithm \\
\hline $\mathrm{VC}(\mathrm{D})$ & Vertical column density \\
\hline WF & Weighting function \\
\hline
\end{tabular}


Acknowledgements. This work has been performed in the frame of the TROPOMI project. We acknowledge financial support from ESA S-5P, Belgium Prodex TRACE-S5P projects, and the Bayerisches Staatsministerium für Wirtschaft und Medien, Energie und Technologie (grant 07 03/893 73/ 5 /2013).

Edited by: J. Kim

Reviewed by: two anonymous referees

\section{References}

Afe, O. T., Richter, A., Sierk, B., Wittrock, F., and Burrows, J. P.: BrO emissions from volcanoes: a survey using GOME and SCIAMACHY measurements, Geophys. Res. Lett., 31, L24113, doi:10.1029/ 2004GL020994, 2004.

Beirle, S., Hörmann, C., Penning de Vries, M., Dörner, S., Kern, C., and Wagner, T.: Estimating the volcanic emission rate and atmospheric lifetime of $\mathrm{SO}_{2}$ from space: a case study for $\mathrm{Ki}$ lauea volcano, Hawai'i, Atmos. Chem. Phys., 14, 8309-8322, doi:10.5194/acp-14-8309-2014, 2014.

Bobrowski, N., Kern, C., Platt, U., Hörmann, C., and Wagner, T.: Novel $\mathrm{SO}_{2}$ spectral evaluation scheme using the 360 $390 \mathrm{~nm}$ wavelength range, Atmos. Meas. Tech., 3, 879-891, doi:10.5194/amt-3-879-2010, 2010.

Boersma, K. F., Eskes, H. J., and Brinksma, E. J.: Error analysis for tropospheric $\mathrm{NO}_{2}$ retrieval from space, J. Geophys. Res., 109, D04311, doi:10.1029/2003JD003962, 2004.

Bogumil, K., Orphal, J., Homann, T., Voigt, S., Spietz, P., Fleischmann, O., Vogel, A., Hartmann, M., Bovensmann, H., Frerick, J., and Burrows, J. P.: Measurements of molecular absorption spectra with the SCIAMACHY Pre-Flight Model: instrument characterization and reference data for atmospheric remotesensing in the 230-2380 nm region, J. Photoch. Photobio. A, 157, 167-184, 2003.

Bovensmann, H., Peuch, V.-H., van Weele, M., Erbertseder, T., and Veihelmann, B.: Report Of The Review Of User Requirements For Sentinels-4/-5, ESA, EOP-SM/2281/BV-bv, issue: 2.1, 2011.

Brenot, H., Theys, N., Clarisse, L., van Geffen, J., van Gent, J., Van Roozendael, M., van der A, R., Hurtmans, D., Coheur, P.-F., Clerbaux, C., Valks, P., Hedelt, P., Prata, F., Rasson, O., Sievers, K., and Zehner, C.: Support to Aviation Control Service (SACS): an online service for near-real-time satellite monitoring of volcanic plumes, Nat. Hazards Earth Syst. Sci., 14, 1099-1123, doi:10.5194/nhess-14-1099-2014, 2014.

Brion, J., Daumont, D., and Malicet, J.: New measurements of the absolute absorption cross-sections of ozone at 294 and $223 \mathrm{~K}$ in the 310-350 nm spectral range, J. Phys., 45, L57-L60, 1984.

Brion, J., Chakir, A., Charbonnier, J., Daumont, D., Parisse, C., and Malicet, J.: Absorption spectra measurements for the ozone molecule in the 350-830 nm region, J. Atmos. Chem., 30, 291299, doi:10.1023/A:1006036924364, 1998.

Carn, S. A. and Lopez, T. M.: Opportunistic validation of sulfur dioxide in the Sarychev Peak volcanic eruption cloud, Atmos. Meas. Tech., 4, 1705-1712, doi:10.5194/amt-4-1705-2011, 2011.

Carn, S. A., Clarisse, L., and Prata, A. J.: Multi-decadal satellite measurements of global volcanic degassing, J. Volcanol. Geoth. Res., 311, 99-134, doi:10.1016/j.jvolgeores.2016.01.002, 2016.
Chance, K. and Spurr, R. J.: Ring effect studies: Rayleigh scattering including molecular parameters for rotational Raman scattering, and the Fraunhofer spectrum, Appl. Opt., 36, 5224-5230, 1997.

Chance, K. and Kurucz, R. L.: An improved high-resolution solar reference spectrum for earth's atmosphere measurements in the ultraviolet, visible, and near infrared, J. Quant. Spectrosc. Ra., 111, 1289-1295, 2010.

Clarisse, L., Fromm, M., Ngadi, Y., Emmons, L., Clerbaux, C., Hurtmans, D., and Coheur, P.-F.: Intercontinental transport of anthropogenic sulfur dioxide and other pollutants; an infrared remote sensing case study, Geophys. Res. Lett., 38, L19806, doi:10.1029/2011GL048976, 2011.

Danielson, J. J. and Gesch, D. B.: Global multi-resolution terrain elevation data 2010 (GMTED2010): US Geological Survey OpenFile Report 2011-1073, 26 pp., 2011.

De Smedt, I., Müller, J.-F., Stavrakou, T., van der A, R., Eskes, H., and Van Roozendael, M.: Twelve years of global observations of formaldehyde in the troposphere using GOME and SCIAMACHY sensors, Atmos. Chem. Phys., 8, 4947-4963, doi:10.5194/acp-8-4947-2008, 2008.

De Smedt, I., Yu, H., Danckaert, T., Theys, N., van Gent, J., Van Roozendael, M., Richter, A., Hilboll, A., Loyola, D., and Veefkind, P.: Formaldehyde retrievals from TROPOMI onboard Sentinel-5 Precursor: Algorithm Theoretical Basis, Atmos. Meas. Tech., in preparation, 2016.

Eisinger, M. and Burrows, J. P.: Tropospheric sulfur dioxide observed by the ERS-2 GOME instrument, Geophys. Res. Lett., 25, 4177-4180, 1998.

Eskes, H. J. and Boersma, K. F.: Averaging kernels for DOAS totalcolumn satellite retrievals, Atmos. Chem. Phys., 3, 1285-1291, doi:10.5194/acp-3-1285-2003, 2003.

Fioletov, V. E., McLinden, C. A., Krotkov, N., Yang, K., Loyola, D. G., Valks, P., Theys, N., Van Roozendael, M., Nowlan, C. R., Chance, K., Liu, X., Lee, C., and Martin, R. V.: Application of OMI, SCIAMACHY, and GOME-2 satellite $\mathrm{SO}_{2}$ retrievals for detection of large emission sources, J. Geophys. Res.-Atmos., 118, 11399-11418, doi:10.1002/jgrd.50826, 2013.

Fioletov, V. E., McLinden, C. A., Krotkov, N., Li, C., Joiner, J., Theys, N., Carn, S., and Moran, M. D.: A global catalogue of large $\mathrm{SO}_{2}$ sources and emissions derived from the Ozone Monitoring Instrument, Atmos. Chem. Phys., 16, 11497-11519, doi:10.5194/acp-16-11497-2016, 2016.

Galle, B., Johansson, M., Rivera, C., Zhang, Y., Kihlman, M., Kern, C., Lehmann, T., Platt, U., Arellano, S., and Hidalgo, S.: Network for Observation of Volcanic and Atmospheric Change (NOVAC) - A global network for volcanic gas monitoring: Network layout and instrument description, J. Geophys. Res., 115, D05304, doi:10.1029/2009JD011823, 2010.

Greenblatt, G. D., Orlando, J. J., Burkholder, J. B., and Ravishankara, A. R.: Absorption measurements of oxygen between 330 and $1140 \mathrm{~nm}$, J. Geophys. Res., 95, 18577-18582, doi:10.1029/JD095iD11p18577, 1990.

He, H., Vinnikov, K. Y., Li, C., Krotkov, N. A., Jongeward, A. R., Li, Z., Stehr, J. W., Hains, J. C. and Dickerson, R. R.: Response of $\mathrm{SO}_{2}$ and particulate air pollution to local and regional emission controls: A case study in Maryland, Earth's Future, 4, 94-109, doi:10.1002/2015EF000330, 2016.

Heue, K.-P., Brenninkmeijer, C. A. M., Wagner, T., Mies, K., Dix, B., Frieß, U., Martinsson, B. G., Slemr, F., and van Velthoven, 
P. F. J.: Observations of the 2008 Kasatochi volcanic $\mathrm{SO}_{2}$ plume by CARIBIC aircraft DOAS and the GOME-2 satellite, Atmos. Chem. Phys., 10, 4699-4713, doi:10.5194/acp-10-4699-2010, 2010.

Heue, K.-P., Brenninkmeijer, C. A. M., Baker, A. K., RautheSchöch, A., Walter, D., Wagner, T., Hörmann, C., Sihler, H., Dix, B., Frieß, U., Platt, U., Martinsson, B. G., van Velthoven, P. F. J., Zahn, A., and Ebinghaus, R.: $\mathrm{SO}_{2}$ and $\mathrm{BrO}$ observation in the plume of the Eyjafjallajökull volcano 2010: CARIBIC and GOME-2 retrievals, Atmos. Chem. Phys., 11, 2973-2989, doi:10.5194/acp-11-2973-2011, 2011.

Hendrick, F., Van Roozendael, M., Kylling, A., Petritoli, A., Rozanov, A., Sanghavi, S., Schofield, R., von Friedeburg, C., Wagner, T., Wittrock, F., Fonteyn, D., and De Mazière, M.: Intercomparison exercise between different radiative transfer models used for the interpretation of ground-based zenith-sky and multi-axis DOAS observations, Atmos. Chem. Phys., 6, 93-108, doi:10.5194/acp-6-93-2006, 2006.

Hermans, C., Vandaele, A. C., and Fally, S.: Fourier transform measurements of $\mathrm{SO}_{2}$ absorption cross sections: I. Temperature dependence in the $24000-29000 \mathrm{~cm}^{-1}$ (345$420 \mathrm{~nm}$ ) region, J. Quant. Spectrosc. Ra., 110, 756-765, doi:10.1016/j.jqstr.2009.01.031, 2009.

Hörmann, C., Sihler, H., Bobrowski, N., Beirle, S., Penning de Vries, M., Platt, U., and Wagner, T.: S ystematic investigation of bromine monoxide in volcanic plumes from space by using the GOME-2 instrument, Atmos. Chem. Phys., 13, 4749-4781, doi:10.5194/acp-13-4749-2013, 2013.

Huijnen, V., Williams, J., van Weele, M., van Noije, T., Krol, M., Dentener, F., Segers, A., Houweling, S., Peters, W., de Laat, J., Boersma, F., Bergamaschi, P., van Velthoven, P., Le Sager, P., Eskes, H., Alkemade, F., Scheele, R., Nédélec, P., and Pätz, H.-W.: The global chemistry transport model TM5: description and evaluation of the tropospheric chemistry version 3.0, Geosci. Model Dev., 3, 445-473, doi:10.5194/gmd-3-445-2010, 2010.

Jin, J., Ma, J., Lin, W., Zhao, H., Shaiganfar, R., Beirle, S., and Wagner, T.: MAX-DOAS measurements and satellite validation of tropospheric $\mathrm{NO}_{2}$ and $\mathrm{SO}_{2}$ vertical column densities at a rural site of North China, Atmos. Environ., 133, 12-25, 2016.

Kelder, H., van Weele, M., Goede, A., Kerridge, B., Reburn, J., Bovensmann, H., Monks, P., Remedios, J., Mager, R., Sassier, H., and Baillon, Y.: Operational Atmospheric Chemistry Monitoring Missions - CAPACITY: Composition of the Atmosphere: Progress to Applications in the user CommunITY, Final Report of ESA contract no. 17237/03/NL/GS, 2005.

Kern, C., Deutschmann, T., Vogel, A., Wöhrbach, M., Wagner, T., and Platt, U.: Radiative transfer corrections for accurate spectroscopic measurements of volcanic gas emissions, B. Volcanol., 72, 233-247, 2009.

Khokhar, M. F., Frankenberg, C., Van Roozendael, M., Beirle, S., Kühl, S., Richter, A., Platt, U., and Wagner, T.: Satellite Observations of Atmospheric $\mathrm{SO}_{2}$ from Volcanic Eruptions during the Time Period of 1996 to 2002, J. Adv. Space Res., 36, 879-887, doi:10.1016/j.asr.2005.04.114, 2005.

Kleipool, Q. L., Dobber, M. R., de Haan, J. F., and Levelt, P. F.: Earth surface reflectance climatology from 3 years of OMI data, J. Geophys. Res., 113, D18308, doi:10.1029/2008JD010290, 2008.
Krotkov, N. A., Carn, S. A., Krueger, A. J., Bhartia, P. K., and Yang, K.: Band residual difference algorithm for retrieval of $\mathrm{SO}_{2}$ from the Aura Ozone Monitoring Instrument (OMI), IEEE Trans. Geosci. Remote Sensing, AURA Special Issue, 44, 1259-1266, doi:10.1109/TGRS.2005.861932, 2006.

Krotkov, N., McClure, B., Dickerson, R., Carn, S., Li, C., Bhartia, P. K., Yang, K., Krueger, A., Li, Z., Levelt, P., Chen, H., Wang, P., and $\mathrm{Lu}, \mathrm{D}$. : Validation of $\mathrm{SO}_{2}$ retrievals from the Ozone Monitoring Instrument over NE China, J. Geophys. Res., 113, D16S40, doi:10.1029/2007JD008818, 2008.

Krotkov, N. A., McLinden, C. A., Li, C., Lamsal, L. N., Celarier, E. A., Marchenko, S. V., Swartz, W. H., Bucsela, E. J., Joiner, J., Duncan, B. N., Boersma, K. F., Veefkind, J. P., Levelt, P. F., Fioletov, V. E., Dickerson, R. R., He, H., Lu, Z., and Streets, D. G.: Aura OMI observations of regional $\mathrm{SO}_{2}$ and $\mathrm{NO}_{2}$ pollution changes from 2005 to 2015, Atmos. Chem. Phys., 16, 46054629, doi:10.5194/acp-16-4605-2016, 2016.

Krueger, A. J.: Sighting of El Chichon sulfur dioxide clouds with the Nimbus 7 total ozone mapping spectrometer, Science, 220 , 1377-1379, 1983.

Langen, J., Meijer, Y., Brinksma, E., Veihelmann, B., and Ingmann, P.: GMES Sentinels 4 and 5 Mission Requirements Document (MRD), ESA, EO-SMA-/1507/JL, issue: 3, 2011.

Lee, C., Martin, R. V., van Donkelaar, A., O’Byrne, G., Krotkov, N., Richter, A., Huey, L. G., and Holloway, J. S.: Retrieval of vertical columns of sulfur dioxide from SCIAMACHY and OMI: Air mass factor algorithm development, validation, and error analysis, J. Geophys. Res., 114, D22303, doi:10.1029/2009JD012123, 2009.

Levelt, P., Veefkind, J., Kerridge, B., Siddans, R., de Leeuw, G., Remedios, J., and Coheur, P.: Observation Techniques and Mission Concepts for Atmospheric Chemistry (CAMELOT), Report, European Space Agency, Noordwijk, the Netherlands, 2009.

Li, C., Joiner, J., Krotkov, N. A., and Bhartia, P. K.: A fast and sensitive new satellite $\mathrm{SO}_{2}$ retrieval algorithm based on principal component analysis: Application to the ozone monitoring instrument, Geophys. Res. Lett., 40, 6314-6318, doi:10.1002/2013GL058134, 2013.

Loyola, D., Garcia, S.G., Lutz, R., and Spurr, R.: S5P Cloud Products ATBD, available at: https://sentinel.esa.int/web/sentinel/ technical-guides/sentinel-5p/appendices/referencesandhttp: //www.tropomi.eu/documents/level-2-products (last access: 6 January 2017), 2016.

Martin, R. V., Chance, K., Jacob, D. J., Kurosu, T. P., Spurr, R. J. D., Bucsela, E., Gleason, J .F., Palmer, P. I., Bey, I., Fiore, A.M., Li, Q., Yantosca, R. M., and Koelemeijer, R. B. A.: An improved retrieval of tropospheric nitrogen dioxide from GOME, J. Geophys. Res., 107, 4437, doi:10.1029/2001JD001027, 2002.

McLinden, C. A., Fioletov, V., Shephard, M. W., Krotkov, N., Li, C., Martin, R. V., Moran, M. D., and Joiner, J.: Space-based detection of missing sulfur dioxide sources of global air pollution, Nat. Geosci., 9, 496-500, doi:10.1038/ngeo2724, 2016.

Nowlan, C. R., Liu, X., Chance, K., Cai, Z., Kurosu, T. P., Lee, C., and Martin, R. V.: Retrievals of sulfur dioxide from the Global Ozone Monitoring Experiment 2 (GOME-2) using an optimal estimation approach: Algorithm and initial validation, J. Geophys. Res., 116, D18301, doi:10.1029/2011JD015808, 2011.

Palmer, P. I., Jacob, D. J., Chance, K. V., Martin, R. V., Spurr, R. J. D., Kurosu, T. P., Bey, I., Yantosca, R., and Fiore, A.: Air 
mass factor formulation for spectroscopic measurements from satellites: Application to formaldehyde retrievals from the Global Ozone Monitoring Experiment, J. Geophys. Res., 106, 1453914550, doi:10.1029/2000JD900772, 2001.

Pedergnana, M., Loyola, D., Apituley, A., Sneep, M., and Veefkind, P.: S5P Level 2 Product User Manual Sulfur Dioxide $\mathrm{SO}_{2}$, available at: https://sentinel.esa.int/web/sentinel/ technical-guides/sentinel-5p/appendices/referencesandhttp:

//www.tropomi.eu/documents/level-2-products (last access: 6 January 2017), 2016.

Platt, U. and Stutz, J.: Differential Optical Absorption Spectroscopy (DOAS), Principle and Applications, ISBN 3-34021193-4, Springer Verlag, Heidelberg, 2008.

Pukīe, J., Kühl, S., Deutschmann, T., Platt, U., and Wagner, T.: Extending differential optical absorption spectroscopy for limb measurements in the UV, Atmos. Meas. Tech., 3, 631-653, doi:10.5194/amt-3-631-2010, 2010.

Richter, A., Wittrock, F., Schönhardt, A., and Burrows, J. P.: Quantifying volcanic $\mathrm{SO}_{2}$ emissions using GOME2 measurements, Geophys. Res. Abstr., EGU2009-7679, EGU General Assembly 2009, Vienna, Austria, 2009.

Richter, A., Begoin, M., Hilboll, A., and Burrows, J. P.: An improved NO2 retrieval for the GOME-2 satellite instrument, Atmos. Meas. Tech., 4, 1147-1159, doi:10.5194/amt-4-1147-2011, 2011.

Rix, M., Valks, P., Hao, N., Loyola, D. G., Schlager, H., Huntrieser, H. H., Flemming, J., Koehler, U., Schumann, U., and Inness, A.: Volcanic $\mathrm{SO}_{2}, \mathrm{BrO}$ and plume height estimations using GOME-2 satellite measurements during the eruption of Eyjafjallajökull in May 2010, J. Geophys. Res., 117, D00U19, doi:10.1029/2011JD016718, 2012.

Sanders, A. and de Haan, J.: S5P ATBD of the Aerosol Layer Height product, available at: https://sentinel.esa.int/web/sentinel/ technical-guides/sentinel-5p/appendices/referencesandhttp: //www.tropomi.eu/documents/level-2-products (last access: 6 January 2017), 2016.

Schumann, U., Weinzierl, B., Reitebuch, O., Schlager, H., Minikin, A., Forster, C., Baumann, R., Sailer, T., Graf, K., Mannstein, H., Voigt, C., Rahm, S., Simmet, R., Scheibe, M., Lichtenstern, M., Stock, P., Rüba, H., Schäuble, D., Tafferner, A., Rautenhaus, M., Gerz, T., Ziereis, H., Krautstrunk, M., Mallaun, C., Gayet, J.F., Lieke, K., Kandler, K., Ebert, M., Weinbruch, S., Stohl, A., Gasteiger, J., Groß, S., Freudenthaler, V., Wiegner, M., Ansmann, A., Tesche, M., Olafsson, H., and Sturm, K.: Airborne observations of the Eyjafjalla volcano ash cloud over Europe during air space closure in April and May 2010, Atmos. Chem. Phys., 11, 2245-2279, doi:10.5194/acp-11-2245-2011, 2011.

Spinei, E., Carn, S. A., Krotkov, N. A., Mount, G. H., Yang, K., and Krueger, A. J.: Validation of ozone monitoring instrument $\mathrm{SO}_{2}$ measurements in the Okmok volcanic plume over Pullman, WA in July 2008, J. Geophys. Res., 115, D00L08, doi:10.1029/2009JD013492, 2010.

Spurr, R.: LIDORT, and VLIDORT: Linearized pseudo-spherical scalar and vector discrete ordinate radiative transfer models for use in remote sensing retrieval problems, Light Scattering Reviews, 3, edited by: Kokhanovsky, A., Springer, 2008.

Spurr, R., de Haan, J. F., van Oss, R., and Vasilkov, A.: Discrete Ordinate Radiative Transfer in a Stratified Medium with First Order
Rotational Raman Scattering, J. Quant. Spectros. Ra., 109, 404425, doi:10.1016/j.jqsrt.2007.08.011, 2008.

Theys, N., Campion, R., Clarisse, L., Brenot, H., van Gent, J., Dils, B., Corradini, S., Merucci, L., Coheur, P.-F., Van Roozendael, M., Hurtmans, D., Clerbaux, C., Tait, S., and Ferrucci, F.: Volcanic $\mathrm{SO}_{2}$ fluxes derived from satellite data: a survey using OMI, GOME-2, IASI and MODIS, Atmos. Chem. Phys., 13, 59455968, doi:10.5194/acp-13-5945-2013, 2013.

Theys, N., De Smedt, I., van Gent, J., Danckaert, T., Wang, T., Hendrick, F., Stavrakou, T., Bauduin, S., Clarisse, L., Li, C., Krotkov, N. A., Yu, H., and Van Roozendael, M.: Sulfur dioxide vertical column DOAS retrievals from the Ozone Monitoring Instrument: Global observations and comparison to groundbased and satellite data, J. Geophys. Res.-Atmos., 120, 24702491, doi:10.1002/2014JD022657, 2015.

Thomas, W., Erbertseder, T., Ruppert, T. van Roozendael, M., Verdebout, J., Balis, D., Meleti, C., and Zerefos, C.: On the retrieval of volcanic sulfur dioxide emissions from GOME backscatter measurements, J. Atmos. Chem., 50, 295-320, doi:10.1007/s10874-005-5544-1, 2005.

Vandaele, A. C., Hermans, C., Simon, P. C., Carleer, M., Colin, R., Fally, S., Mérienne, M. F., Jenouvrier, A., and Coquart, B.: Measurements of the $\mathrm{NO}_{2}$ absorption cross-section from $42000 \mathrm{~cm}^{-1}$ to $10000 \mathrm{~cm}^{-1}(238-1000 \mathrm{~nm})$ at $220 \mathrm{~K}$ and 294 K, J. Quant. Spectrosc. Ra., 59, 171-184, 1998.

Vandaele, A. C., Hermans, C., and Fally, S.: Fourier transform measurements of $\mathrm{SO}_{2}$ absorption cross sections: II. Temperature dependence in the $29000-44000 \mathrm{~cm}^{-1}$ (227$345 \mathrm{~nm}$ ) region, J. Quant. Spectrosc. Ra., 110, 2115-2126, doi:10.1016/j.jqsrt.2009.05.006, 2009.

van $\operatorname{der}$ A, R. J., Mijling, B., Ding, J., Koukouli, M. E., Liu, F., Li, Q., Mao, H., and Theys, N.: Cleaning up the air: Effectiveness of air quality policy for $\mathrm{SO}_{2}$ and $\mathrm{NO}_{x}$ emissions in China, Atmos. Chem. Phys. Discuss., doi:10.5194/acp-2016-445, in review, 2016.

van Geffen, J., van Roozendaal, M., Rix, M., and Valks, P.: Initial Validation of GOME-2 GDP 4.2 $\mathrm{SO}_{2}$ Total Columns-ORR B, TN-IASB-GOME2-O3MSAF-SO $2-01$, September, 2008.

van Geffen, J. H. G. M., Boersma, K. F., Eskes, H. J., Maasakkers, J. D., and Veefkind, J. P. : S5P $\mathrm{NO}_{2}$ data products ATBD, available at: https://sentinel.esa.int/web/sentinel/ technical-guides/sentinel-5p/appendices/referencesandhttp:

//www.tropomi.eu/documents/level-2-products (last access: 6 January 2017), 2016.

van Weele, M., Levelt, P., Aben, I., Veefkind, P., Dobber, M., Eskes, H., Houweling, S., Landgraf, J., and Noordhoek, R.: Science Requirements Document for TROPOMI. Volume 1, KNMI \& SRON, RS-TROPOMI-KNMI-017, issue: 2.0, 2008.

Veefkind, J. P., Aben, I., McMullan, K., Förster, H., de Vries, J., Otter, G., Claas, J., Eskes, H. J., de Haan, J. F., Kleipool, Q., van Weele, M., Hasekamp, O., Hoogeven, R., Landgraf, J., Snel, R., Tol, P., Ingmann, P., Voors, R., Kruizinga, B., Vink, R., Visser, H., and Levelt, P. F.: TROPOMI on the ESA Sentinel-5 Precursor: A GMES mission for global observations of the atmospheric composition for climate, air quality and ozone layer applications, Remote Sens. Environ., 120, 70-83, doi:10.1016/j.rse.2011.09.027, 2012. 
Vountas, M., Rozanov, V. V., and Burrows, J. P.: Ring effect: impact of rotational Raman scattering on radiative transfer in earth's atmosphere, J. Quant. Spectrosc. Ra., 60, 943-961, 1998.

Wagner, T., Burrows, J. P., Deutschmann, T., Dix, B., von Friedeburg, C., Frieß, U., Hendrick, F., Heue, K.-P., Irie, H., Iwabuchi, H., Kanaya, Y., Keller, J., McLinden, C. A., Oetjen, H., Palazzi, E., Petritoli, A., Platt, U., Postylyakov, O., Pukite, J., Richter, A., van Roozendael, M., Rozanov, A., Rozanov, V., Sinreich, R., Sanghavi, S., and Wittrock, F.: Comparison of box-airmass-factors and radiances for Multiple-Axis Differential Optical Absorption Spectroscopy (MAX-DOAS) geometries calculated from different UV/visible radiative transfer models, Atmos. Chem. Phys., 7, 1809-1833, doi:10.5194/acp-7-1809-2007, 2007.

Wang, Y., Beirle, S., Lampel, J., Koukouli, M., De Smedt, I., Theys, N., Xie, P. H., Van Roozendael, M., and Wagner, T.: Validation of OMI and GOME-2A and GOME-2B tropospheric $\mathrm{NO}_{2}$, $\mathrm{SO}_{2}$ and $\mathrm{HCHO}$ products using MAX-DOAS observations from 2011 to 2014 in Wuxi, China, Atmos. Chem. Phys. Discuss., doi:10.5194/acp-2016-735, in review, 2016.

Yang, K., Krotkov, N., Krueger, A., Carn, S., Bhartia, P. K., and Levelt,P.: Retrieval of Large Volcanic $\mathrm{SO}_{2}$ columns from the Aura Ozone Monitoring Instrument (OMI): Comparisons and Limitations, J. Geophys. Res., 112, D24S43, doi:10.1029/2007JD008825, 2007.
Yang, K., Liu, X., Bhartia, P., Krotkov, N., Carn, S., Hughes, E., Krueger, A., Spurr, R., and Trahan, S.: Direct retrieval of sulfur dioxide amount and altitude from spaceborne hyperspectral UV measurements: Theory and application, J. Geophys. Res., 115, D00L09, doi:10.1029/2010JD013982, 2010.

Yang, K., Dickerson, R. R., Carn, S. A., Ge, C., and Wang, J.: First observations of $\mathrm{SO}_{2}$ from the satellite Suomi NPP OMPS: Widespread air pollution events over China, Geophys. Res. Lett., 40, 4957-4962, doi:10.1002/grl.50952, 2013.

Zhou, Y., Brunner, D., Boersma, K. F., Dirksen, R., and Wang, P.: An improved tropospheric $\mathrm{NO}_{2}$ retrieval for OMI observations in the vicinity of mountainous terrain, Atmos. Meas. Tech., 2, 401-416, doi:10.5194/amt-2-401-2009, 2009.

Zweers, S.: S5P ATBD for the UV aerosol index, available at: https://sentinel.esa.int/web/sentinel/technical-guides/ sentinel-5p/appendices/references and http://www.tropomi. eu/documents/level-2-products (last access: 6 January 2017), 2016.

Zweers, S., Levelt, P. F., Veefkind, J. P., Eskes, H., de Leeuw, G, Tamminen, J., Coheur, P. F., Prunet, P., and Camy-Peyret, C.: TRAQ Performance Analysis and Requirements Consolidation for the Candidate Earth Explorer Mission TRAQ, Final report, KNMI, RP-ONTRAQ-KNMI-051, issue: 1.0, 2010. 